\title{
Nickel-Catalysed Vapour-Phase Hydrogenation of Furfural, Insights into Reactivity and Deactivation
}

\author{
Kathryn L. MacIntosh ${ }^{1}\left[\right.$ (]) Simon K. Beaumont ${ }^{1}$ (])
}

Published online: 30 July 2020

(c) The Author(s) 2020

\begin{abstract}
Furfural is a key bioderived platform molecule, and its hydrogenation affords access to a number of important chemical intermediates that can act as "drop-in" replacements to those derived from crude oil or novel alternatives with desirable properties. Here, the vapour phase hydrogenation of furfural to furfuryl alcohol at $180{ }^{\circ} \mathrm{C}$ over standard impregnated nickel catalysts is reported and contrasted with the same reaction over copper chromite. Whilst the selectivity to furfuryl alcohol of the unmodified nickel catalysts is much lower than for copper chromite as expected, the activity of the nickel catalysts in the vapour phase is significantly higher, and the deactivation profile remarkably similar. In the case of the supported nickel catalysts, possible contribution to the deactivation by acidic sites on the catalyst support is discounted based on the similarity of deactivation kinetics on $\mathrm{Ni} / \mathrm{SiO}_{2}$ with those seen for less acidic $\mathrm{Ni} / \mathrm{TiO}_{2}$ and $\mathrm{Ni} / \mathrm{CeO}_{2}$. Powder X-ray diffraction is used to exclude sintering as a primary deactivation pathway. Significant coking of the catalyst $(\sim 30 \mathrm{wt} \%$ over $16 \mathrm{~h})$ is observed using temperature programmed oxidation. This, in combination with the solvent extraction analysis and infrared spectroscopy of the coked catalysts points to deactivation by polymeric condensation products of (reactant or) products and hydrocarbon like coke. These findings pave the way for targeted modification of nickel catalysts to use for this important biofeedstock-to-chemicals transformation.
\end{abstract}

Keywords Nickel catalyst $\cdot$ Hydrogenation $\cdot$ Deactivation $\cdot$ Furfural $\cdot$ Platform molecule

\section{Introduction}

In the quest to use bio-derived chemical feedstocks to displace the use of dwindling reserves of crude oil, a number of platform molecules have been identified that could act as chemical intermediates in future biorefineries [1]. Furfural was identified as one of the most promising molecules for sustainable production of fuels and chemicals in the twentyfirst century [2], and is readily obtainable via the acid catalysed hydrolysis of C5 sugars [3-6]. Furfural can be used directly as a process agent in lubricant oil manufacture or in the flavourings and perfume industry, but most of the current feedstock ( 60\%) [4] is hydrogenated to furfuryl alcohol for use as an adhesive, resin or corrosion resistant coating [7, 8]. As shown in Fig. 1, a number of other important chemical intermediates can also be produced via furfural.

Simon K. Beaumont

simon.beaumont@durham.ac.uk

1 Department of Chemistry, University of Durham, Durham DH1 3LE, UK
Key to the realization of biorefineries (using furfural and other platform molecules) is the development of new catalytic processes that are able to selectively transform biomass derived oxygen-rich molecules into either "drop in" replacement chemicals and fuels, or completely new intermediates with desirable properties.

Currently, hydrogenation of furfural to furfuryl alcohol is typically conducted with a copper chromite catalyst which risks damage to human health and the environment via toxic $\mathrm{Cr}(\mathrm{VI})$ [9]. The process has typically been conducted in batch at high pressures of hydrogen [4], and is thus not attractive for large scale applications. Furthermore when conducted in vapour phase or trickle bed reactors, significant deactivation has been seen to occur $[10,11]$. Other catalysts suffer due to expensive cost-for instance a number of studies of precious metal catalysts have been explored [12-16].

In general, an effective and low cost metal associated with simple hydrogenation transformations (CO methanation; hydrogenation of vegetable oils) is nickel [17]. Deactivation over $\mathrm{Ni}$ catalysts is common, and is largely attributed to coke formation as Ni strongly adsorbs carbon [18]. In more 


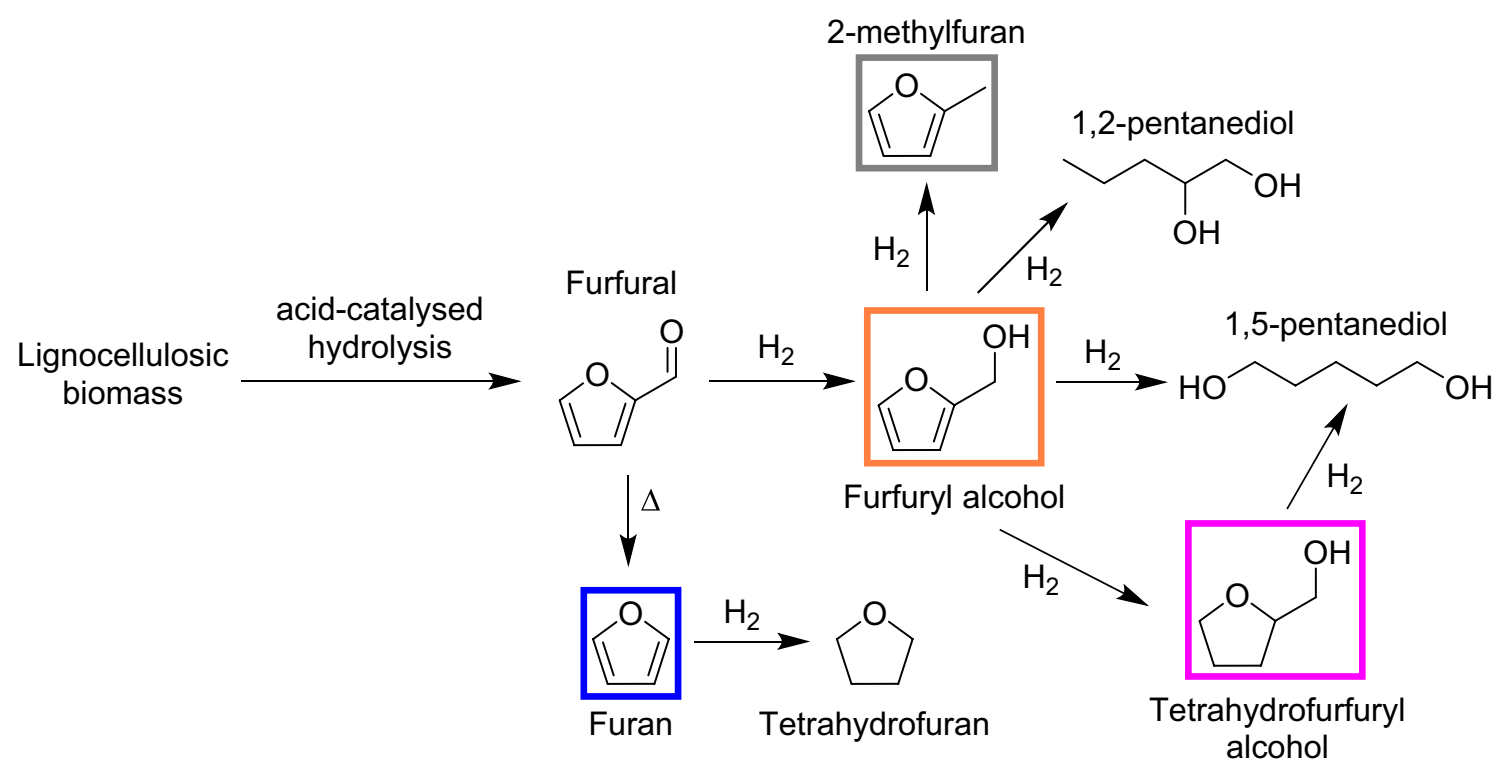

Fig. 1 Scheme showing products formed during the hydrogenation of furfural

complex transformations such as stream reforming, nickel is also widely used [19], however deactivation by coking of the catalyst remains a challenge and therefore efforts have been made to understand and inhibit carbon deposition in this context [20,21].

Nickel and modified nickel/bimetallic catalysts have been explored for selective reactions of furfural, in both liquidphase [22-31] and vapour-phase [32-36] hydrogenations, but commonly exhibit deactivation. In this paper we benchmark the chemistry of furfural hydrogenation on nickel using a simply-prepared, incipient wetness silica-supported catalyst, characterising the intrinsic activity, selectivity and the deactivation profile and contrasting these with copper chromite. We then examine the deactivation of the catalyst and coke species that form on the catalyst's surface. This provides key information in understanding the challenges in modifying the performance of nickel catalysts to produce the needed efficient, selective materials for this important biorefinery transformation.

\section{Experimental}

\subsection{Materials}

Deionised water was obtained from a Purite Neptune and had a resistivity $\leq 18 \mathrm{M} \Omega$. All gases were obtained from BOC and had a minimum purity of $99.99 \%$. All gases used in catalyst pre-treatment, temperature programmed reduction and furfural hydrogenation were further purified and dried using zeolite and activated carbon filters. The silica and titania catalyst supports were obtained from commercial sources:
Cab-O-Sil M5 silica (CABOT) and P25 titania (Evonik). The ceria support and KIT-6 silica used for hard-templating of the ceria were both synthesised in-house using the standard procedures detailed below. $\mathrm{Ni}\left(\mathrm{NO}_{3}\right)_{2} \cdot 6 \mathrm{H}_{2} \mathrm{O}$, ethanol (HPLC grade) and dichloromethane (analytical grade) were purchased from Fisher Scientific. Furfural (99\%), cerium nitrate hexahydrate (99\%), tetraethyl orthosilicate (98\%), Pluronic 123 (average $\mathrm{M}_{\mathrm{n}} \sim 5800$ ) and $\mathrm{Na}_{2} \mathrm{CO}_{3}(99.5-100.5 \%$ ) were purchased from Sigma Aldrich. The furfural was purified via vacuum distillation from $\mathrm{Na}_{2} \mathrm{CO}_{3}$ before use [37]. All other compounds were used as received.

\subsection{Synthesis of KIT-6 Silica}

The KIT-6 silica was prepared following the method outlined by Pirez et al. [38] P123 (6.0 g) was added to a mixture of deionised water $(217 \mathrm{~mL})$ and concentrated $\mathrm{HCl}(11.8 \mathrm{~g})$ in a polypropylene bottle. The obtained mixture was stirred at $35^{\circ} \mathrm{C}$ until homogeneous. 1-Butanol $(6.0 \mathrm{~g})$ was then added to the mixture and it was stirred at $35^{\circ} \mathrm{C}$ for $1 \mathrm{~h}$. Then, tetraethyl orthosilicate (TEOS) $(12.9 \mathrm{~g})$ was added and the mixture was stirred at $35{ }^{\circ} \mathrm{C}$ for $24 \mathrm{~h}$ before it was aged at $100{ }^{\circ} \mathrm{C}$ (without stirring, sealed in the polypropylene bottle) for a further $24 \mathrm{~h}$. The solid product was isolated by filtration whilst hot and without washing, and then dried at $100{ }^{\circ} \mathrm{C}$ in static air for $24 \mathrm{~h}$. Then product was calcined to remove the template material by heating to $550{ }^{\circ} \mathrm{C}$ at a rate of $1{ }^{\circ} \mathrm{C} \mathrm{min}-1$ and holding at $550{ }^{\circ} \mathrm{C}$ for $6 \mathrm{~h}$ in static air. 


\subsection{Synthesis of Mesoporous $\mathrm{CeO}_{2}$}

The mesoporous ceria was prepared based on methods outlined by Bruce et al. [39] and Tuysuz et al. [40] $\mathrm{Ce}\left(\mathrm{NO}_{3}\right)_{3} \cdot 6 \mathrm{H}_{2} \mathrm{O}(1.5 \mathrm{~g})$ was dissolved in ethanol $(20 \mathrm{~mL})$, followed the addition of KIT- 6 silica $(1 \mathrm{~g})$. The mixture was stirred at room temperature open to air until a nearly dry powder was obtained $(\sim 36 \mathrm{~h})$. Then the sample was calcined by heating to $500{ }^{\circ} \mathrm{C}$ at a rate of $1{ }^{\circ} \mathrm{C} / \mathrm{min}$ and kept at $500{ }^{\circ} \mathrm{C}$ for $6 \mathrm{~h}$. To remove the KIT- 6 silica template, the resulting sample was added to $2 \mathrm{M} \mathrm{NaOH}(20 \mathrm{~mL})$ in a polypropylene bottle and heated to $70{ }^{\circ} \mathrm{C}$ for around $24 \mathrm{~h}$. The resulting mixture was centrifuged $(8000 \mathrm{rpm}, 10 \mathrm{~min})$ to separate the solid, which was added to a further portion of $2 \mathrm{M} \mathrm{NaOH}(20 \mathrm{~mL})$ in a polypropylene bottle. This mixture was sonicated to disperse the solid before being heated to $90{ }^{\circ} \mathrm{C}$ for $\sim 24 \mathrm{~h}$. The sample was then separated via centrifugation ( $8000 \mathrm{rpm}, 10 \mathrm{~min}$ ). The solid was washed thrice with deionised water and then dried at $60{ }^{\circ} \mathrm{C}$ overnight.

\subsection{Synthesis of Supported $\mathrm{Ni}\left(\mathrm{NO}_{3}\right)_{2}$ Catalysts (Supports- $\mathrm{SiO}_{2}, \mathrm{TiO}_{2}, \mathrm{CeO}_{2}$ ) via Incipient Wetness}

To prepare a nominally $5 \mathrm{wt} \% \mathrm{Ni} / \mathrm{SiO}_{2}$ catalyst, the silica (Cab-O-Sil) was first dried for a minimum of $4 \mathrm{~h}$ in a vacuum oven at $120^{\circ} \mathrm{C}$. The dried silica $(4.10 \mathrm{~g})$ was placed in a round bottom flask or conical flask. $\mathrm{Ni}\left(\mathrm{NO}_{3}\right)_{2} \cdot 6 \mathrm{H}_{2} \mathrm{O}(1.07 \mathrm{~g})$ was dissolved in deionised water $(12.7 \mathrm{~mL}$ ) (as determined by the pore volume of the support). The $\mathrm{Ni}\left(\mathrm{NO}_{3}\right)_{2} \cdot 6 \mathrm{H}_{2} \mathrm{O}$ solution was added dropwise to the silica with frequent mixing using a vortex mixer to ensure an even distribution. The impregnated silica was then dried overnight in an oven at $120{ }^{\circ} \mathrm{C}$ and then further dried in a vacuum oven for a minimum of $4 \mathrm{~h}$ at $120{ }^{\circ} \mathrm{C}$. The nominally $5 \mathrm{wt} \% \mathrm{Ni} / \mathrm{TiO}_{2}$ and $\mathrm{Ni} / \mathrm{CeO}_{2}$ catalysts were prepared in an analogous manner $\left(\mathrm{Ni} / \mathrm{TiO}_{2}: \mathrm{P} 25\right.$ titania (dried) $0.5048 \mathrm{~g}, \mathrm{Ni}\left(\mathrm{NO}_{3}\right)_{2} \cdot 6 \mathrm{H}_{2} \mathrm{O}$ $0.1348 \mathrm{~g}$, deionised water $0.55 \mathrm{~mL} ; \mathrm{Ni} / \mathrm{CeO}_{2}$ : mesoporous ceria (dried) $0.1324 \mathrm{~g}, \mathrm{Ni}\left(\mathrm{NO}_{3}\right)_{2} \cdot 6 \mathrm{H}_{2} \mathrm{O} 0.0355 \mathrm{~g}$, deionised water $0.1 \mathrm{~mL})$.

\subsection{Vapor-Phase Furfural Hydrogenation}

Furfural hydrogenation was carried out in a fixed bed reactor, consisting of a 1/4 inch stainless steel tube that sat inside a tube furnace. Gases were delivered by computer controlled MKS mass flow controllers. Unreduced catalyst (10-100 mg as necessary to obtain comparable / desired catalyst activities) was added to the reactor tube supported by a glass rod and glass wool. Catalyst reduction was accomplished in situ in $30 \mathrm{~mL} \mathrm{~min}^{-1}$ of hydrogen by heating to $500{ }^{\circ} \mathrm{C}$ at a rate of $15{ }^{\circ} \mathrm{C} \mathrm{min}{ }^{-1}$ and holding at $500{ }^{\circ} \mathrm{C}$ for $2 \mathrm{~h}$ before cooling to the reaction temperature of $180{ }^{\circ} \mathrm{C}$. These conditions were selected based on the optimum reported in the prior work by Nakagawa [33]. The $\mathrm{Ni} / \mathrm{TiO}_{2}$ and the copper chromite catalysts required lower reduction temperatures and were heated to $300{ }^{\circ} \mathrm{C}$ ( still at a rate of $15{ }^{\circ} \mathrm{C} \mathrm{min}-1$ ) under the same hydrogen flow $\left(30 \mathrm{~mL} \mathrm{~min}^{-1}\right)$, but held for longer at $300{ }^{\circ} \mathrm{C}$ ( $3 \mathrm{~h}$ for $\mathrm{Ni} / \mathrm{TiO}_{2}$ and $4 \mathrm{~h}$ for copper chromite), before cooling to the reaction temperature of $180^{\circ} \mathrm{C}$. The conditions for copper chromite activation were taken from literature protocols [41], and the conditions for $\mathrm{Ni} / \mathrm{TiO}_{2}$ were established experimentally, since lowering the reduction temperature to $300{ }^{\circ} \mathrm{C}$ gave an approximately three-fold more active catalyst, but did not significantly affect selectivity. The decrease in activity is entirely consistent with the well-known strong metal support interaction (SMSI) effect [42], whereby $\mathrm{TiO}_{2}$ diffuses onto the metal surfaces (including nickel specifically [43]) as a result of reduction at $500{ }^{\circ} \mathrm{C}$ or above, in this case reducing access to the nickel.

During furfural hydrogenation, the hydrogen flow rate was increased to $70 \mathrm{~mL} \mathrm{~min}^{-1}$ and distilled furfural was supplied at a rate of $0.0138 \mathrm{~mL} \mathrm{~min}^{-1}$ using a syringe pump (World Precision Instruments, molar $\mathrm{H}_{2}$ :furfural ratio 19:1). The furfural and hydrogen passed into a vaporizer, which consisted of a stainless steel ConFlat full nipple containing glass beads for heat transfer and was heated to $170{ }^{\circ} \mathrm{C}$ using heat tapes, as monitored by a K-type thermocouple positioned within the vaporizer. All tubing/components after the vaporizer were heat traced $\left(160-220^{\circ} \mathrm{C}\right)$ to prevent condensation. The catalyst bed was kept at $180{ }^{\circ} \mathrm{C}$ during reaction, with temperature feedback provided by a K-type internal thermocouple that sat just above the catalyst bed. Typical runs lasted around $16 \mathrm{~h}$. The reactor effluent was connected to a six-way Vici-Valco sampling valve, before venting via a cold trap. The samples from the valve were injected into a Hewlett Packard HP 5890 gas chromatograph (GC) with a flame ionisation detector (FID), equipped with a SGE BP5 $30 \mathrm{~m}$ column (ID: $0.53 \mathrm{~mm}$; film thickness: $1 \mu \mathrm{m})$. Samples were collected automatically (around $5 \mathrm{~h}^{-1}$ ) and analysed using the GCFID (Oven temperature programme: $4 \mathrm{~min}$ at $60{ }^{\circ} \mathrm{C}$, then heated to $140{ }^{\circ} \mathrm{C}$ (heating rate of $20^{\circ} \mathrm{C} \mathrm{min}{ }^{-1}$ ) and held at $140{ }^{\circ} \mathrm{C}$ for $1 \mathrm{~min}$ ). Calibrations of the FID sensitivity factors and GC retention times were conducted by initially identifying products from the cold trap after reaction using an off-line GC-MS and then injecting commercial samples of the identified products into the online GC to calculate FID sensitivity factors and confirm retention times. Selectivity was calculated as the fraction: (moles of a given product)/(moles of all detected products) and expressed as a percentage. Selectivity was seen to be stable after the first few hours in all cases (even though conversion decreased during a run), therefore data was averaged over a period from $\sim 5$ to $10 \mathrm{~h}$ time on stream (TOS) to obtain the most accurate values possible for smaller components 
in the product mixture. To obtain results for consistent conversion profiles conversion at $5 \mathrm{~h}$ TOS were targeted to be $\sim 25 \%$ (and were all within the range $10-40 \%$ ). Given that no strong selectivity variations were seen over time as catalysts deactivated across this conversion range, this eliminated the possibility that variations in selectivity seen were the result of obtaining measurements at substantially different conversions, or from catalysts experiencing different mass transport regimes. Conversion was calculated as the fraction: (moles of all products detected)/(initial moles of furfural). The carbon mass balance was seen to be close to unity within experimental sensitivity and reproducibility (overall $<10 \%$ ) and does not change noticeably as a function of time, although as discussed in the deactivation section, some deposition of carbonaceous materials must be occurring. Errors shown are based on 4 repeat measurements of a typical sample (the standard error in the mean for the $\mathrm{Ni} / \mathrm{SiO}_{2}$ sample as this was reproduced 4 times to get an estimate of reproducibility, or standard error in this typical sample where applied to samples repeated a smaller number of times).

\subsection{Testing the Acidity of the Supports Using Hammett Indicators}

Portions of the supports $\left(\mathrm{SiO}_{2}: 100 \mathrm{mg}\right.$; $\mathrm{TiO}_{2}: 100 \mathrm{mg}$; $\mathrm{CeO}_{2}: 25 \mathrm{mg}$ ) were dried in an oven for $2 \mathrm{~d}$ at $120^{\circ} \mathrm{C}$ and then further dried in a vacuum oven at $120{ }^{\circ} \mathrm{C}$ for $4 \mathrm{~h}$. The samples were then dispersed in dry toluene $\left(\mathrm{SiO}_{2}\right.$ and $\mathrm{TiO}_{2}$ : $4 \mathrm{~mL} ; \mathrm{CeO}_{2}: 2 \mathrm{~mL}$ ). Methyl red and methyl yellow indicator solutions were prepared by dissolving methyl red $(10 \mathrm{mg})$ or methyl yellow $(10 \mathrm{mg})$ in dry toluene $(10 \mathrm{~mL}) .1-2$ drops of either the methyl red or methyl yellow indicator solution was added to the support/toluene suspensions.

\subsection{Soxhlet Extraction of Coke Species on Spent Catalysts}

Spent $\mathrm{Ni} / \mathrm{SiO}_{2}$ catalyst $(10 \mathrm{mg})$ was placed into an extraction thimble. Dichloromethane (DCM) $(100 \mathrm{~mL})$ was used as the extraction solvent. DCM was refluxed in the Soxhlet extraction apparatus for $\sim 2$ days. The resulting solution was concentrated under reduced pressure and then dissolved in a minimal volume of DCM $(<0.5 \mathrm{~mL})$. This sample, along with a sample of DCM for reference were analysed by gas chromatography-mass spectrometry (GC-MS). GC-MS analysis was carried out using a Shimadzu QP2010-Ultra with a Rxi-5Sil MS $10 \mathrm{~m}$ column (column ID: $0.15 \mathrm{~mm}$; column film thickness: $0.15 \mu \mathrm{m}$; oven temperature program: $30{ }^{\circ} \mathrm{C}$ for $1 \mathrm{~min}$, heat to $300{ }^{\circ} \mathrm{C}$ at a rate of $50{ }^{\circ} \mathrm{C} \mathrm{min}^{-1}$ and hold at $300{ }^{\circ} \mathrm{C}$ for $5 \mathrm{~min}$ ).

\subsection{Transmission Electron Microscopy (TEM)}

TEM imaging was carried out using a JEOL 2100F FEG microscope with a Schottky field emitter at $200 \mathrm{keV}$. Samples were dispersed in ethanol by sonication and deposited onto 300 mesh copper grids with a carbon film (EM Resolutions). All samples were reduced prior to analysis, however they were exposed to air before analysis. A number of areas (at least 6) were sampled in order to ensure images selected were representative of the sample. A particle size distribution and mean particle size were obtained from counting $\sim 40$ particles that were clearly visible and counting all clearly discriminated particles within a given region to minimize bias.

\subsection{Powder X-Ray Driffraction (pXRD)}

pXRD patterns were acquired using a Bruker AXS D8 Advance diffractometer, fitted with a Lynxeye Soller PSD detector and controlled by Diffrac and XRD commander software. Samples were placed on a low background silicon sample holder (silicon wafer (100)-cut off orientation $9^{\circ}$ towards (001), Sil'tronix Silicon Technologies, mounted in a plastic puck). Copper $\mathrm{K} \alpha_{1}(\lambda=1.5406 \AA)$ and $\mathrm{K} \alpha_{2}(\lambda=1.5444 \AA)$ radiation was used. Patterns were recorded with a $2 \theta$ range of $10-90^{\circ}$ and a typical scan lasted $\sim 110 \mathrm{~min}$. All samples were reduced prior to analysis, however they were exposed to air before and during analysis.

MATLAB was used to apply an exponential background to the section of the data in the $2 \theta$ range of $23-50^{\circ}$ and fit a Gaussian function to the $\mathrm{Ni}$ (111) reflection at $44.5^{\circ}$. This gave the full width at half maximum (FWHM) of the reflection, permitting crude estimation of the crystallite size using the Scherrer equation:

$\beta(2 \theta)=\frac{K \lambda}{L \cos (\theta)}$

where $\beta(2 \theta)=$ peak width (FWHM) of reflection at angle $2 \theta$ in radians, $\mathrm{K}=$ dimensionless shape factor (taken to be 0.9 ), $\lambda=$ wavelength of radiation in $\mathrm{nm}, \mathrm{L}=$ average crystallite size in $\mathrm{nm}$ and $\theta=$ angle of reflection in radians.

\subsection{Inductively Couple Plasma-Optical Emission Spectroscopy (ICP-OES)}

Samples were prepared by digesting a small amount of catalyst (typically $20 \mathrm{mg}$ ) in around $3 \mathrm{~mL}$ of aqua regia (3:1 v/v conc. $\mathrm{HCl}$ : conc. $\mathrm{HNO}_{3}$ ) at $80^{\circ} \mathrm{C}$ for $1 \mathrm{~h}$. After cooling, these solutions were diluted with deionised water using volumetric flasks to achieve a solution with a metal concentration of around $80 \mathrm{mg} \mathrm{L}^{-1}$. Controls were prepared from 
the water-soluble salt precursor $\mathrm{Ni}\left(\mathrm{NO}_{3}\right)_{2} \cdot 6 \mathrm{H}_{2} \mathrm{O}$, and used to confirm the absence of any significant deviations on a given run. The required amount of the salt was dissolved and diluted in aqua regia and deionised water, ensuring both the metal and acid concentrations matched that of the digested samples. All samples were prepared in duplicate.

A Jobin Yvon Horiba Ultima 2 instrument was used to carry out the ICP-OES analysis. This instrument is comprised of a sequential monochromator, a radial torch, a cyclonic spray chamber, a concentric nebuliser and a high dynamic detector. The nickel content was determined from the emission line at $231.604 \mathrm{~nm}$. The instrument was calibrated before the samples were measured using a commercial Ni calibration standard of known metal content.

\subsection{BET Surface Area via $\mathrm{N}_{2}$ Adsorption}

The BET surface area of ceria was measured by nitrogen adsorption and desorption at $77 \mathrm{~K}$ using a Micromeritics ASAP 2020 volumetric adsorption analyzer. Samples were degassed at $350{ }^{\circ} \mathrm{C}\left(\right.$ ramp rate: $10{ }^{\circ} \mathrm{C} \mathrm{min}^{-1}$ ) for $4 \mathrm{~h}$ under dynamic vacuum before analysis. $\mathrm{P} / \mathrm{P}_{0}$ values between $0.05-0.25$ were used in the BET calculation for evaluation of the surface area.

\subsection{Thermogravimetric Analysis (TGA)/ Temperature Programmed Oxidation (TPO)}

A Perkin Elmer TGA 8000 was used for TGA/TPO analysis of small quantities of post-reaction sample. Samples were heated from room temperature at a rate of $5{ }^{\circ} \mathrm{C} \mathrm{min}^{-1}$ or $2{ }^{\circ} \mathrm{C} \mathrm{min}-1$ as indicated in flowing air for the spent silica samples and spent $\mathrm{Ni} / \mathrm{SiO}_{2}$ catalyst respectively.

\subsection{Temperature Programmed Reduction (TPR)}

Impregnated catalyst $(50 \mathrm{mg}$ ) was added to a quartz tube, supported with quartz wool, placed inside a tube furnace and connected to gas lines via Ultra-torr type fittings. Gas flows were set to $10 \mathrm{~mL} \mathrm{~min}{ }^{-1}$ of hydrogen and $40 \mathrm{~mL} \mathrm{~min}^{-1}$ of nitrogen. The outlet of the quartz tube was connected to a calcium chloride column to remove water before the gases were analysed with a homebuilt thermal conductivity detector (TCD). The hydrogen amount represented by TPR peaks was calibrated by TPR of known masses of $\mathrm{CuO}$ diluted in $\mathrm{SiC}\left(\mathrm{CuO}+\mathrm{H}_{2} \rightarrow \mathrm{Cu}+\mathrm{H}_{2} \mathrm{O} ; 3\right.$ different masses, each run in duplicate).

\subsection{Diffuse Reflectance Infrared Fourier Transform Spectroscopy (DRIFTS)}

DRIFTS measurements were carried out using a Nicolet iS10 FTIR spectrometer, fitted with a Praying Mantis diffuse reflection accessory. Samples were analysed for 32 scans with a resolution of $0.5 \mathrm{~cm}^{-1}$. Samples were diluted in $\mathrm{KBr}$ (10 mg sample; $400 \mathrm{mg} \mathrm{KBr}$ ) and samples were typically backgrounded against the relevant fresh, organic-free catalyst support diluted in $\mathrm{KBr}$ (10 mg support; $400 \mathrm{mg} \mathrm{KBr}$ ). For the spent nickel powder spectra, pre-reaction nickel powder diluted in $\mathrm{KBr}$ was used as the background.

\subsection{Attenuated Total Reflectance-Fourier Transform Infrared Spectroscopy (ATR-FTIR)}

ATR-FTIR measurements were carried out using a PerkinElmer Frontier FTIR, fitted with a Specac Quest GS10800 ATR accessory (resolution: $1 \mathrm{~cm}^{-1}$ ).

\section{Results and Discussion}

\subsection{Synthesis and Characterization of $\mathrm{Ni} / \mathrm{SiO}_{2}$ Catalyst}

The nickel catalysts in this work were prepared using a widely employed and straightforward approach, impregnating the metal oxide with nickel nitrate salt. We primarily focus on $\mathrm{Ni} / \mathrm{SiO}_{2}$, however $\mathrm{Ni} / \mathrm{CeO}_{2}$ and $\mathrm{Ni} / \mathrm{TiO}_{2}$ have also been prepared in an analogous manner to investigate the possible role of the support (discussed later). Since the direct reduction of $\mathrm{Ni}\left(\mathrm{NO}_{3}\right)_{2} / \mathrm{SiO}_{2}$ after impregnation, rather than with a calcination step before reduction, has been shown to give superior reactivity for furfural hydrogenation, this approach was adopted throughout the current work [33]. ICP-OES confirmed the loading of the $\mathrm{Ni} / \mathrm{SiO}_{2}$ catalyst to be $4.82 \mathrm{wt} \%$ nickel, in good agreement with the nominal 5 $\mathrm{wt} \%$ target loading. The reduction process was examined in more detail by TPR (Fig. 2). For the $\mathrm{SiO}_{2}$-supported sample, there was one sharp peak at $263{ }^{\circ} \mathrm{C}$ and a shoulder at $304^{\circ} \mathrm{C}$. These were deconvoluted as shown in Fig. $2 b$, with the first and second fitted peaks corresponding to $0.91( \pm 0.04)$ and $0.98( \pm 0.08) \mathrm{H}_{2}$ molecules per nickel atom, respectively. As both components correspond to around one $\mathrm{H}_{2}$ molecule per nickel atom present, this is consistent with a 2 -step reduction process, as reported previously (Scheme 1) [33, 44]. The lower temperature peak is slightly sub-stoichiometric, although not to the same extent as observed elsewhere [33]. Any sub-stoichiometric consumption of $\mathrm{H}_{2}$ in the lower temperature peak (nitrate reduction) has been proposed in the literature to result from the formation of basic nitrate species such as $\mathrm{Ni}\left(\mathrm{NO}_{3}\right)_{2} \cdot 2 \mathrm{Ni}(\mathrm{OH})_{2}$, which can form during the drying of impregnated catalysts [44]. The ceria and titania cases are less well resolved and consume more hydrogen, likely due to the fact these supports themselves are reducible in nature, but it can be noted that reduction processes are complete by $300{ }^{\circ} \mathrm{C}$. 
(a)

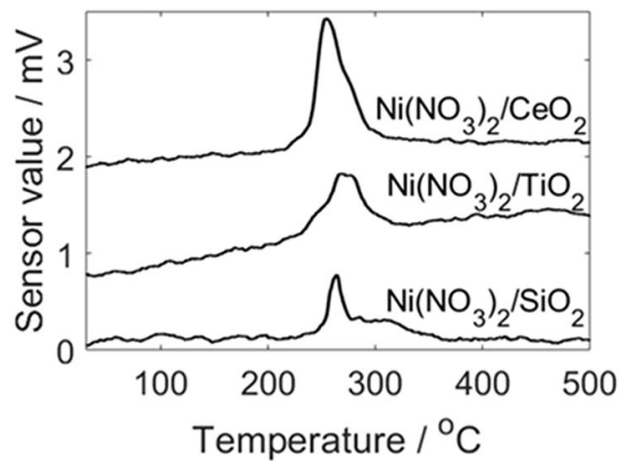

(b)

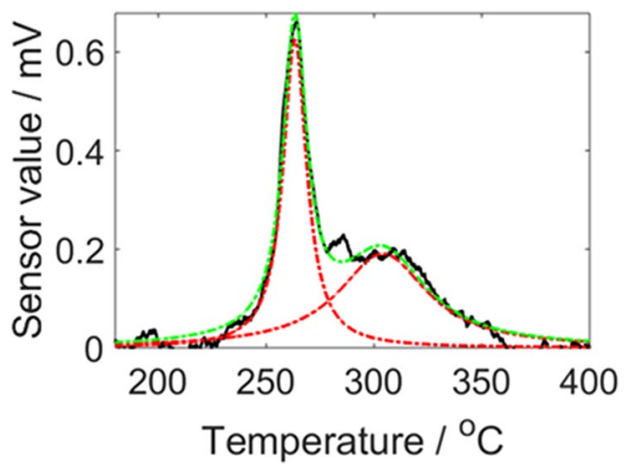

Fig. 2 a Showing TPR profiles showing the consumption of hydrogen for $\mathrm{Ni}\left(\mathrm{NO}_{3}\right)_{2}$ impregnated ceria, titania and silica, and $\mathbf{b}$ showing a deconvolution of the data for $\mathrm{Ni}\left(\mathrm{NO}_{3}\right)_{2}$ impregnated $\mathrm{SiO}_{2}$, which has two clear components $\left(20 \mathrm{v} / \mathrm{v} \% \mathrm{H}_{2}\right.$ in $\mathrm{N}_{2}$, total gas flow rate $50 \mathrm{~mL} \mathrm{~min}^{-1}$, heating rate $5{ }^{\circ} \mathrm{C} \mathrm{min}^{-1}$ )

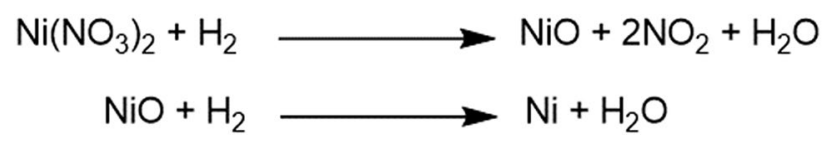

Scheme 1 Reactions steps occurring during a 2-step reduction process for $\mathrm{Ni}\left(\mathrm{NO}_{3}\right)_{2}$ to nickel metal

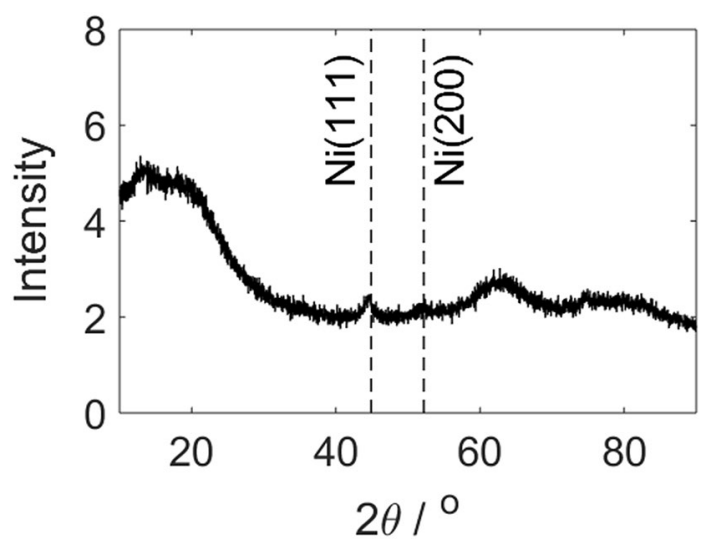

Fig. 3 pXRD pattern of post-reduction $\mathrm{Ni} / \mathrm{SiO}_{2}$ sample, the positions of metallic f.c.c. nickel reflections are marked by the vertical dashed lines
Figure 3 shows the pXRD pattern from a sample of the $\mathrm{Ni} / \mathrm{SiO}_{2}$ catalyst after reduction. The presence of reflections attributable to nickel metal can be clearly seen and the average metal crystallite size was estimated to be $7 \pm 1 \mathrm{~nm}$. Figure 4a shows TEM images of the $\mathrm{Ni}\left(\mathrm{NO}_{3}\right)_{2} / \mathrm{SiO}_{2}$ sample after reduction, showing silica (light) with a broad size distribution (Fig. 4b) of nickel metal particles (dark features). The mean size from TEM was found to be $7 \pm 6 \mathrm{~nm}$, similar to that found by pXRD, although some caution is needed with TEM derived sizes for $\mathrm{Ni} / \mathrm{SiO}_{2}$ catalysts due to the small difference in imaging contrast.

\subsection{Furfural Hydrogenation over $\mathrm{Ni} / \mathrm{SiO}_{2}$}

The $\mathrm{Ni} / \mathrm{SiO}_{2}$ catalyst exhibited similar selectivity at both low ( $37 \%$ at $5 \mathrm{~h} \mathrm{TOS}$ ) and high ( $82 \%$ at $5 \mathrm{~h}$ TOS) conversion (see Fig. 5), with around a 50\% selectivity to the desired furfuryl alcohol product. From the low conversion data (where mass transport and/or equilibrium effects are less significant) the intrinsic mass activity was found to be $622 \pm 192 \mathrm{mmol}_{\text {(prod) }}$ $\mathrm{g}_{\text {(cat) }}{ }^{-1} \mathrm{~h}^{-1}$ after $1 \mathrm{~h}$ time on stream (TOS). However, as seen from Fig. 6a, moderately rapid deactivation occurred, and so after $5 \mathrm{~h}$ TOS the mass activity had almost halved to $329 \pm 109 \mathrm{mmol}_{\text {(prod) }} \mathrm{g}_{\text {(cat) }}{ }^{-1} \mathrm{~h}^{-1}$. It should be noted that the purification of furfural by distillation to a colourless liquid and storage at $-18{ }^{\circ} \mathrm{C}[12,37,45]$, sealed away from air and light was found to be crucial in obtaining both reproducible conversions and longevity of the catalyst, but is only reported in handful of papers. It is reported that this discolouration of furfural via a yellow to a brown/black liquor results from highly conjugated oligomeric impurities, which form due to hydrogen abstraction by oxygen acting as a diradical [45]. Even though these are thought to be present at $\ll 1 \%$, we found incorrect storage or the absence of purification resulted in much more rapid deactivation and complete loss of activity during furfural hydrogenation.

A comparison to literature results for $\mathrm{Ni} / \mathrm{SiO}_{2}, \mathrm{Ni}$ /“"Othersupport" and copper chromite catalysts is given in Table 1 . Such comparisons are inevitably fraught with inconsistencies in the method used; those at lower temperature likely involve a condensed phase on the catalyst and different Furfural: $\mathrm{H}_{2}$ ratios have been used. Nevertheless, Table 1 shows that the vapour phase reaction is catalysed effectively by $\mathrm{Ni} / \mathrm{SiO}_{2}$, but not with the selectivity reported at much lower temperature. The results obtained here are similar to those obtained with a much higher Ni loading mixed metal oxide catalyst. Interestingly, there are also some less active but more selective Ni based catalysts in the literature examples identified, which importantly implies that modifications to Ni to trade-off activity versus selectivity are possible and could be searched for in future catalyst design. Perhaps the most important contrasts, however, are to copper chromite. Two striking comparisons can be drawn: 
(a)
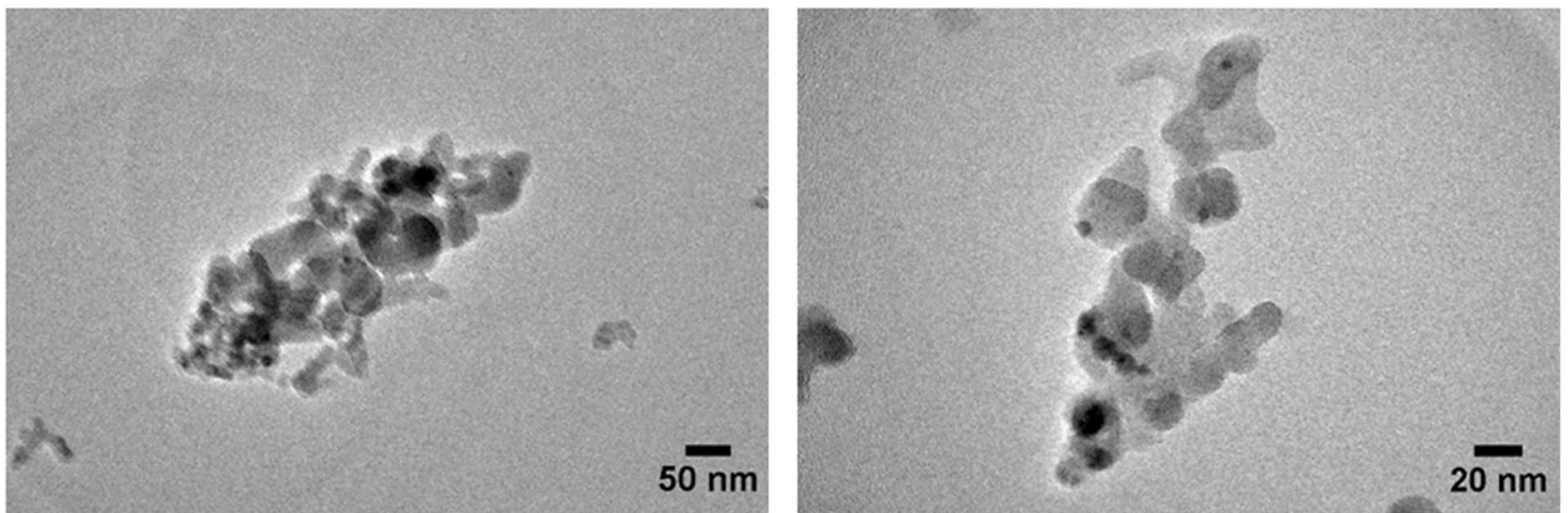

(b)

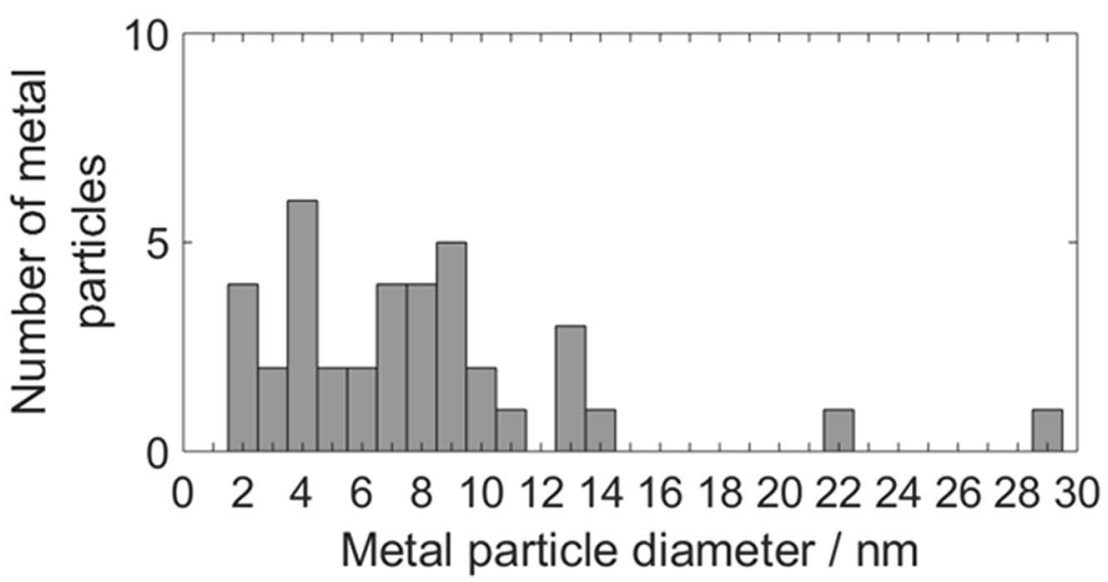

Fig. 4 a Showing TEM images of post-reduction $\mathrm{Ni} / \mathrm{SiO}_{2}$ and $\mathbf{b}$ corresponding particle size distribution

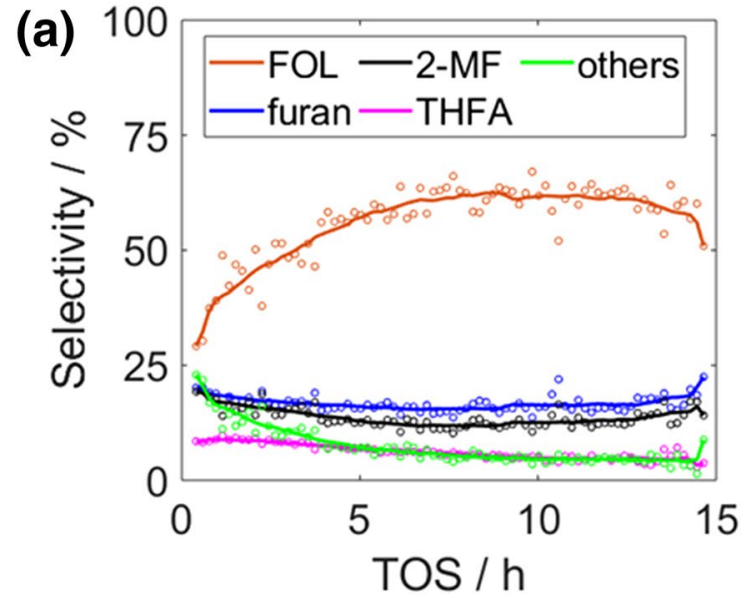

Fig. 5 a An example of selectivity as a function of time on stream (TOS) at low conversion ( $37 \%$ at $5 \mathrm{~h}$ TOS); b Comparison of low ( $37 \%$ at $5 \mathrm{~h}$ TOS) and high conversion (82\% at $5 \mathrm{~h}$ TOS) $\mathrm{Ni} / \mathrm{SiO}_{2}$ average selectivity under stable operation. Errors shown are based on repeat measurements of a typical sample as indicated in the experi-

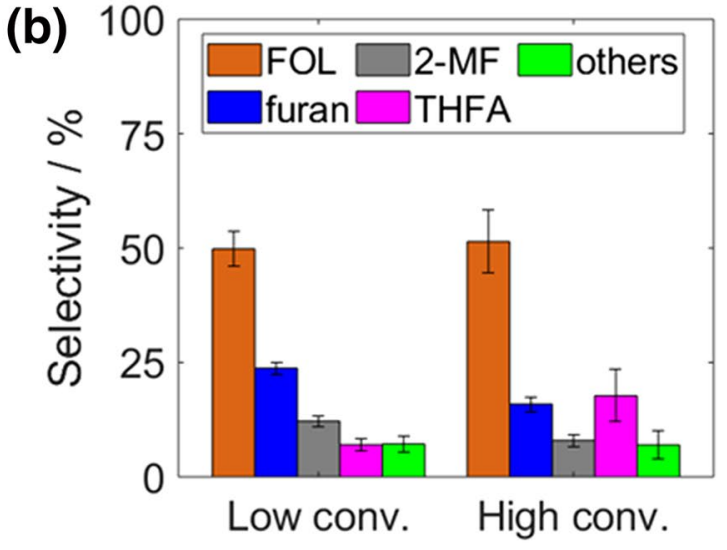

mental section. Key to product abbreviations: FOLfurfuryl alcohol, 2-MF 2-methyl furan, furan furan, THFA tetrahydrofurfuryl alcohol, others are predominantly butanal, 1-butanol, 2-methyl tetrahydrofuran and tetrahydrofuran 


\section{(a)}

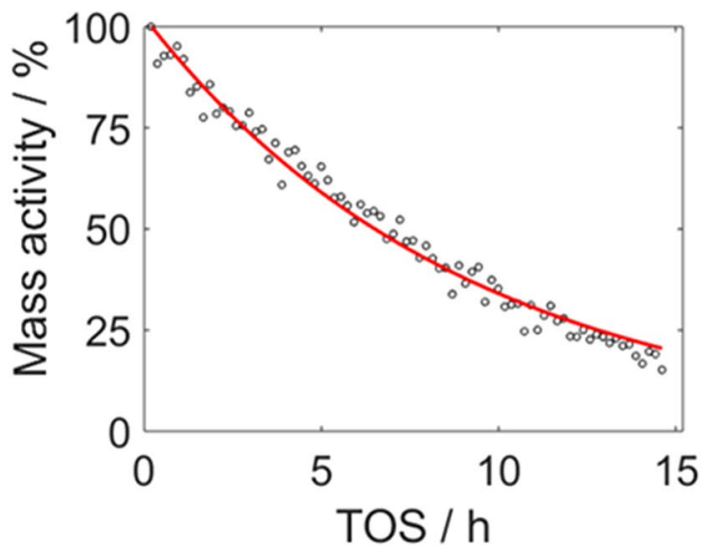

Fig. 6 Deactivation profile showing mass activity as a function of time on stream for a a typical $\mathrm{Ni} / \mathrm{SiO}_{2}$ catalyst under the same conditions as the 'low conversion' sample in in Fig. 5a and $\mathbf{b}$ a copper (b)

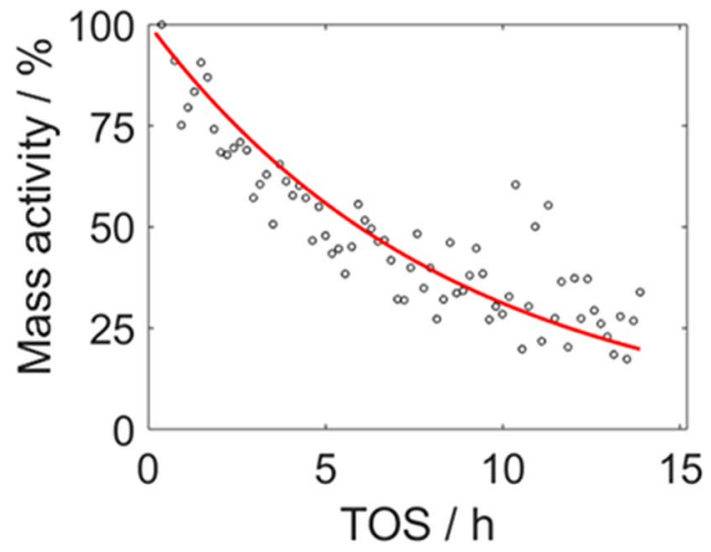

chromite catalyst,. Red lines are a fit to a 1st order kinetic decay. Mass activity shown as a percentage of initial value to facilitate comparison
Table 1 Comparison of the catalysts in this report and literature nickel and benchmark copper chromite catalysts run in vapour phase or pseudo-vapour phase (trickle bed) continuous reactors; mass activities were calculated at low conversions where possible, how-

\begin{tabular}{|c|c|c|c|c|c|}
\hline Catalyst & $\begin{array}{l}\text { Ni or } \mathrm{Cu} \text { load- } \\
\text { ing (wt } \%)\end{array}$ & $\begin{array}{l}\text { Tempera- } \\
\text { ture }\left({ }^{\circ} \mathrm{C}\right)\end{array}$ & $\begin{array}{l}\text { Selectivity to furfu- } \\
\text { ryl alcohol (\%) }\end{array}$ & $\begin{array}{l}\text { Mass activity after } 5 \mathrm{~h} \text { TOS } \\
\left(\mathrm{mmol}_{\text {prod }} \mathrm{g}_{\text {cat }}^{-1} \mathrm{~h}^{-1}\right)\end{array}$ & Furfural: $\mathrm{H}_{2}$ ratio \\
\hline $\mathrm{Ni} / \mathrm{SiO}_{2}$ (this work) & 5 & 180 & 50 & $329(622)^{\mathrm{a}}$ & $1: 19$ \\
\hline $\mathrm{Ni} / \mathrm{SiO}_{2}[33]$ & 10 & 130 & 95 & $91^{\mathrm{b}}$ & $1: 18$ \\
\hline Ni/SBA-15 [36] & 20 & 170 & 53 & 5.5 & $1: 12$ \\
\hline $1.1 \mathrm{Ni}-0.8 \mathrm{Co}-\mathrm{Al}$ mixed metal oxide [34] & 57 & 155 & 79 & $440^{\mathrm{a}}$ & $1: 25$ \\
\hline Mg:Al:Ni (MAN-2) [32] & 48.3 & 180 & 89 & 32 & $1: 3$ \\
\hline Ni/carbon-silica (15Ni/RHCS) [35] & 15 & 180 & 96 & 11 & $1: 7$ \\
\hline $\mathrm{Ni} / \mathrm{TiO}_{2}$ (this work) & 5 & 180 & 55 & 73 & $1: 19$ \\
\hline $\mathrm{Ni} / \mathrm{CeO}_{2}$ (this work) & 5 & 180 & 58 & 49 & $1: 19$ \\
\hline Copper chromite (this work) & 40 & 180 & 98 & 23 & $1: 19$ \\
\hline Copper chromite (Cu 1800P) [11] & $40^{\mathrm{c}}$ & 200 & 96 & $42^{\mathrm{d}}$ & $1: 25$ \\
\hline Copper chromite (Cu 1800P) [47] & $40^{\mathrm{c}}$ & 180 & 99 & 9 & $1: 2.5$ \\
\hline Copper chromite [10] & 40 & 200 & 94 & 18 & $1: 25$ \\
\hline
\end{tabular}

ever some examples only included data for close to $100 \%$ conversion; ${ }^{\mathrm{a}}$ mass activity after $1 \mathrm{~h}$ TOS; ${ }^{\mathrm{b}}$ mass activity after $0.5 \mathrm{~h}$ TOS; ${ }^{\mathrm{c} e s t i-}$ mated value since this is a commercial sample and the exact composition is unknown; ${ }^{\mathrm{d}}$ mass activity at $4 \mathrm{~h}$ TOS

Selectivity to furfu- Mass activity after $5 \mathrm{~h}$ TOS Furfural $: \mathrm{H}_{2}$ ratio (1)

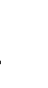




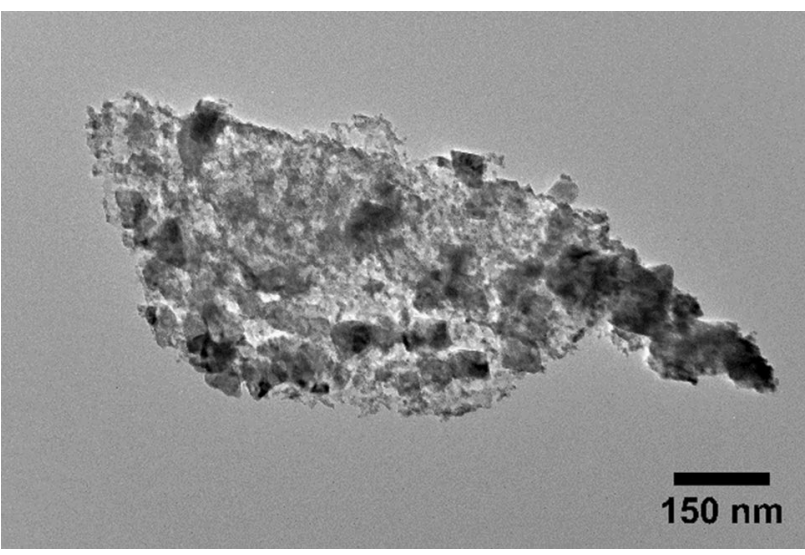

Fig. 7 TEM image of the copper chromite catalyst

Copper chromite was found to be almost $100 \%$ selective for furfuryl alcohol at low conversion (13\% at $5 \mathrm{~h}$ TOS), with small amounts of 2-methylfuran as a minor side product (see Fig. 8), in contrast to the $\mathrm{Ni} / \mathrm{SiO}_{2}$ catalyst, which-at similar conversions-had a selectivity of $\sim 50 \%$ to furfuryl alcohol and formed of range of by-products. However, the mass activity of the $\mathrm{Ni} / \mathrm{SiO}_{2}$ catalyst is an order of magnitude higher than the copper chromite catalyst, despite the fact that the copper chromite catalyst contains around 40 $\mathrm{wt} \%$ copper whereas the nickel catalyst contains only around $5 \mathrm{wt} \%$ nickel. The copper chromite catalyst also exhibits moderately rapid deactivation (Fig. 6b). If the deactivation is fitted to a rate equation that assumes simple 1st order kinetics (to minimise the effect of the time the first reaction sample is taken), both $\mathrm{Ni} / \mathrm{SiO}_{2}$ and copper chromite catalysts produce similar deactivation rate constants, as seen in Fig. 8c. Since widespread wisdom is that copper chromite catalysts have good stability in a range of other reactions [48], it was somewhat unexpected for the catalyst to exhibit rapid deactivation similar to that of the nickel catalysts. However, the deactivation of copper chromite in this reaction has been highlighted by others $[10,11]$. The underlying mechanism of the furfural hydrogenation reaction over copper chromite, while debated, is thought to involve $\mathrm{Cu}^{+}$oxidic (a)

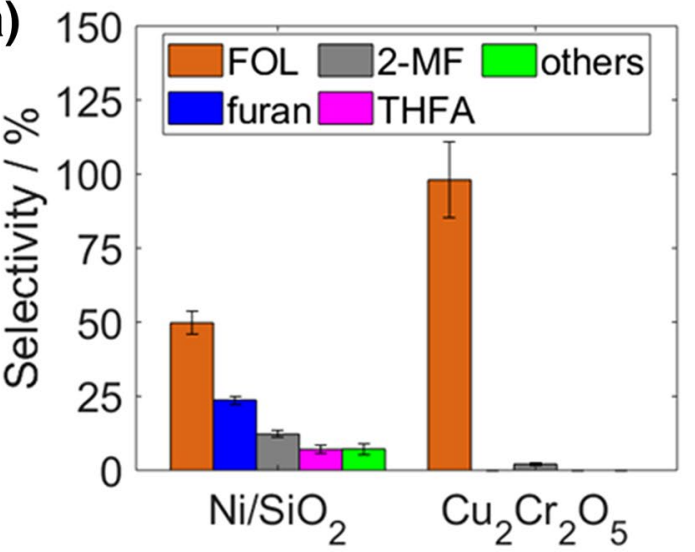

(b)

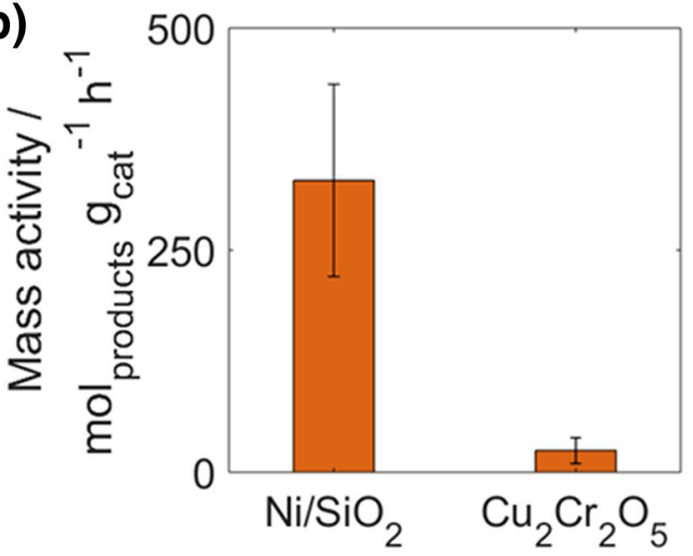

(c)

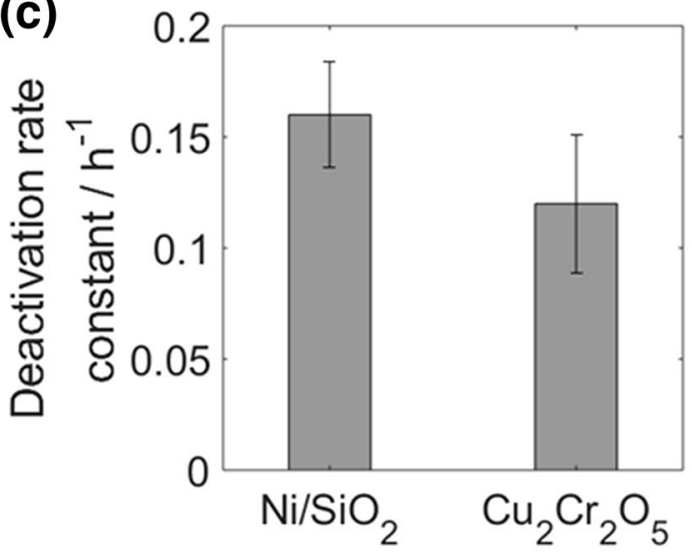

Fig. 8 Comparison of $\mathrm{Ni} / \mathrm{SiO}_{2}$ and copper chromite during furfural hydrogenation. a Average selectivity under stable operation; b Mass activity after $5 \mathrm{~h}$ TOS; c Deactivation rate constants. Errors shown are based on repeat measurements of a typical sample as indicated in the experimental section. Key to product abbreviations: FOL furfuryl alcohol, 2-MF 2-methyl furan, furan = furan, THFA tetrahydrofurfuryl alcohol, others are predominantly butanal, 1-butanol, 2-methyl tetrahydrofuran and tetrahydrofuran 
sites by parallels to other reduction reactions over copper chromite [49], but it has also been suggested to involve copper metal for hydrogen dissociation [41]. If the latter is true, then speculatively metal site blocking by carbon may be responsible in both cases, which is perhaps the simplest explanation for the very similar deactivation behaviour.

\subsection{Furfural Hydrogenation over Ni on Less Acidic Catalysts Supports}

The use of silica supports, whose surfaces contain acidic silanol groups, raises the possibility that these sites can catalyse unwanted side reactions that contribute to the deactivation seen above. Specifically furfural and furfuryl alcohol polymerisation can be acid catalysed, which may promote coke formation. To address this question, two further catalysts were prepared in an analogous manner on two nonacidic supports: titania and ceria. While in general terms silica is known to contain acidic surface hydroxyls, while the other two oxides are not (except when present in mixed oxides such as titania-silica) [50], we have also demonstrated this point by a simple Hammett indicator test using methyl red. Methyl red changes colour in solution from yellow above $\mathrm{pH} 6.2$ through orange to red at $\mathrm{pH} 4.2(\mathrm{pKa}=4.8)$. As can be seen in Fig. 9, the indicator, which is an orange colour in toluene turns slightly darker orange for ceria, slightly more pink for titania and quite distinctly magenta/red for the $\mathrm{SiO}_{2}$, confirming their surface acidity is expected to be in the order $\mathrm{SiO}_{2}>\mathrm{TiO}_{2}>\mathrm{CeO}_{2}$. (Notably none of the oxide supports exhibit a change in the presence of methyl yellow $[\mathrm{pKa}=3.3]$.) While the point of using different supports was to explore the impact of support acid sites and we have not investigated these materials in detail, it was important to consider the exposed surface area of the support if this was responsible for unwanted side reactions. A commercial $\mathrm{TiO}_{2}$ powder with slightly lower surface area was used, but for the $\mathrm{CeO}_{2}$ it was found necessary to prepare a mesoporous ceria

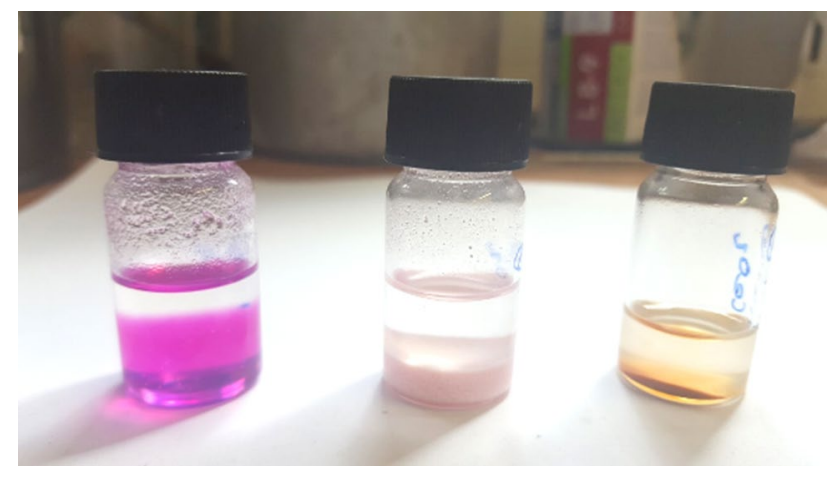

Fig. 9 Photograph showing colour change on exposure of different oxide supports to and adsorption of the Hammett indicator methyl red in toluene solution: silica (left); titania (middle); ceria (right)
Table 2 BET surface areas of the different supports; "avalue obtained from specification documentation provided by the supplier

\begin{tabular}{ll}
\hline Support & $\begin{array}{l}\text { BET surface } \\
\text { area }\left(\mathrm{m}^{2} \mathrm{~g}^{-1}\right)\end{array}$ \\
\hline Cab-O-Sil M5 silica & $200^{\mathrm{a}}$ \\
Aeroxide P25 titania & $35-65^{\mathrm{a}}$ \\
Mesoporous ceria (prepared in-house) & 152 \\
\hline
\end{tabular}

to obtain a material of comparable surface area to the silica. While it might have been possible to prepare more similar support materials, as will be shown very little variation with support was seen, so this was not investigated further. Their surface areas are reported in Table 2.

As seen from the catalysis results shown in Fig. 10a, exchanging the catalyst support for these more basic analogues did not significantly influence the selectivity of the catalysts, implying that selectivity is predominantly controlled by the metal. Furthermore, using the same approach as above and fitting the deactivation as a simple 1st order kinetic process (Fig. 10b) results in very similar deactivation rate constants for all the catalysts (the $\mathrm{TiO}_{2}$ supported sample appears slightly lower, but this may be within error, or else is only a small difference). The mass activity (Fig. 10c) of the titania and ceria supported catalysts was lower than that of the silica supported catalyst, but this could easily result from particle size effects and was unimportant from the point of view of understanding deactivation, so was not investigated further. The key observation is that the slightly acidic silanol groups in the silica support are not a significant factor in catalyst deactivation.

\subsection{Characterisation of Deactivated Catalyst Materials}

To better understand the deactivation processes occurring, further measurements of the spent catalysts (used at $180{ }^{\circ} \mathrm{C}$ during furfural hydrogenation for $\sim 16 \mathrm{~h}$ TOS) were undertaken. Deactivation processes are likely to involve either sintering of the highly dispersed nickel or coking of the metal particles' surfaces. To rule out the possibility that sintering was the primary culprit, pXRD was used to estimate the crystallite size in the post-reaction $\mathrm{Ni} / \mathrm{SiO}_{2}$ sample. It should be noted pXRD alone must be used to identify possible sintering, rather than pXRD and TEM, because of the impossibility of extracting the spent catalyst from the insoluble carbon deposited, which interferes with imaging. The pXRD pattern obtained after $16 \mathrm{~h}$ TOS (Fig. 11) is very similar to that shown for the freshly reduced catalyst in Fig. 3, with slight narrowing of the $\mathrm{Ni}$ (111) reflection, corresponding to an average crystallite size of around $10 \mathrm{~nm}$ compared to around $7 \mathrm{~nm}$ pre-reaction. At most this corresponds to a 

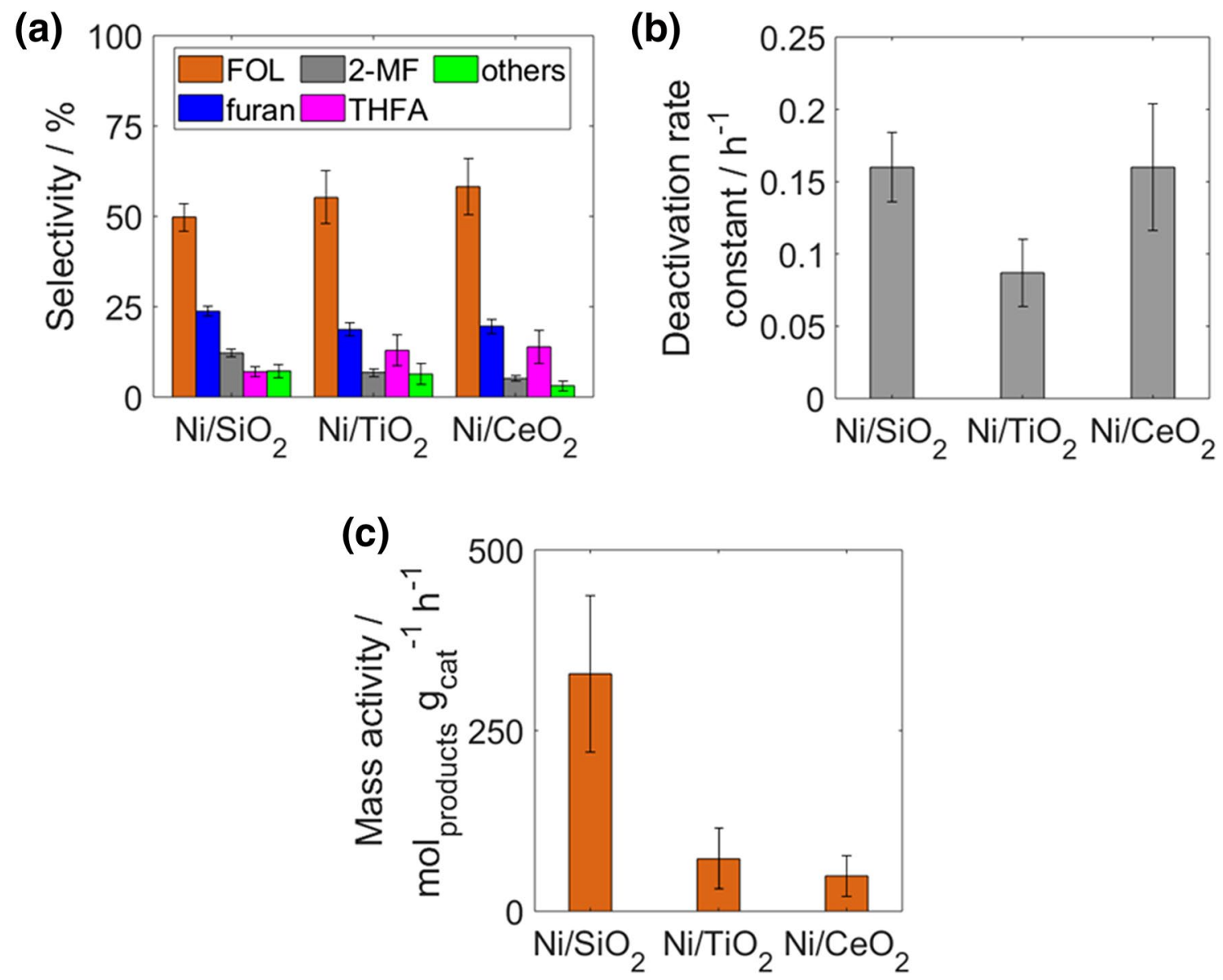

Fig. 10 Comparison of different supports during furfural hydrogenation. a Average selectivity under steady operation; b Deactivation rate constants; c Mass activities after $5 \mathrm{~h}$ TOS. Errors shown are based on repeat measurements of a typical sample as indicated in the experi- mental section. Key to product abbreviations: FOLfurfuryl alcohol, 2-MF 2-methyl furan, furan furan, THFA tetrahydrofurfuryl alcohol, others are predominantly butanal, 1-butanol, 2-methyl tetrahydrofuran and tetrahydrofuran

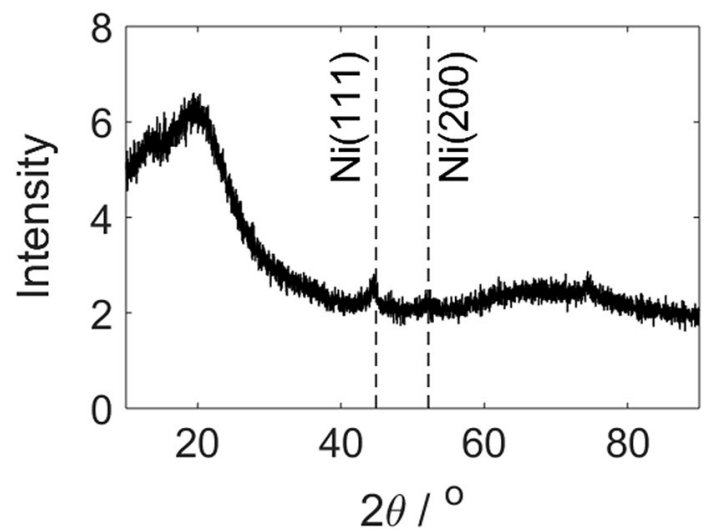

Fig. 11 pXRD pattern of post-reaction $\mathrm{Ni} / \mathrm{SiO}_{2}$ sample, the positions of metallic f.c.c. nickel reflections are marked by the vertical dashed lines
Table 3 The mass losses from TPO data for silica exposed to furfural or furfuryl alcohol under standard reaction conditions and spent catalysts $\left(\mathrm{Ni} / \mathrm{SiO}_{2}\right.$ and copper chromite)

\begin{tabular}{ll}
\hline Sample & Mass loss $(\%)$ \\
\hline Furfural- $\mathrm{SiO}_{2}$ & 9.5 \\
Furfuryl alcohol- $\mathrm{SiO}_{2}$ & 10 \\
Spent $\mathrm{Ni} / \mathrm{SiO}_{2}$ & 30 \\
Spent copper chromite & 1.3 \\
\hline
\end{tabular}

Mass losses below $200{ }^{\circ} \mathrm{C}$ attributable to water, and the mass gain for the copper chromite sample attributable to oxidation $\left(<320^{\circ} \mathrm{C}\right)$ were excluded as not part of the carbon-containing mass loss of interest

surface area decrease of 50\% (assuming spherical particles), whereas the activity drops by as much as an order of magnitude over a typical reaction run. Consequently, sintering alone cannot account for the deactivation observed.

The results of TPO experiments to investigate the possible processes that contribute to coking of the catalyst surface 
are given in Table 3. In order to investigate the role of the support in coking, silica was exposed to furfural and furfuryl alcohol (the major reaction product) in the reactor under standard conditions and then subjected to TGA in air, along with a post-reaction $\mathrm{Ni} / \mathrm{SiO}_{2}$ catalyst. The post-reaction $\mathrm{Ni} /$ $\mathrm{SiO}_{2}$ catalyst exhibited a loss of around $30 \mathrm{wt} \%$ by $500{ }^{\circ} \mathrm{C}$, suggesting significant coking of the catalyst. Both furfural$\mathrm{SiO}_{2}$ and furfuryl alcohol- $\mathrm{SiO}_{2}$ samples showed a weight loss, although significantly less than the spent $\mathrm{Ni} / \mathrm{SiO}_{2}$ catalyst ( $<15 \mathrm{wt} \%)$. Differential mass loss analysis for the TPO experiments (Fig. 12) revealed that both of the silica samples and the spent $\mathrm{Ni} / \mathrm{SiO}_{2}$ catalyst all had a peak at around $300{ }^{\circ} \mathrm{C}$, however the spent catalyst had a second peak at a higher temperature (around $450{ }^{\circ} \mathrm{C}$ ). Therefore, when nickel is present, a second coke species forms. This means that although the silica does likely contribute to coking during reaction, the nickel metal is playing a significant role in coke formation.

It is instructive to consider the spatial volume of the coke present on the post-reaction $\mathrm{Ni} / \mathrm{SiO}_{2}$ catalyst sample. A reasonable ballpark estimate of metal surface area is of order $5 \mathrm{~m}^{2} \mathrm{~g}^{-1}$ (based on assuming the particles are spherical, with the density of bulk nickel and the size of the crystallites observed by pXRD). A $15 \mathrm{wt} \%$ loss (roughly corresponding to either the 300 or $450{ }^{\circ} \mathrm{C}$ mass loss feature) if assumed to be present as a hydrocarbon (density $\sim 1 \mathrm{~g} \mathrm{~cm}^{-3}$ ) equates to $0.18 \mathrm{~cm}^{3} \mathrm{~g}_{\text {cat }}{ }^{-1}$ of hydrocarbon material. In contrast the $\mathrm{Ni}$ volume is $\sim 5 \times 10^{-3} \mathrm{~cm}^{3} \mathrm{~g}_{\text {cat }}{ }^{-1}$, a difference of around 30 times. (The same arguments may be rehearsed with graphitic carbon (density $2.3 \mathrm{gcm}^{-3}$ ) and the volume ratio of coke:Ni still large, $~ 15: 1$.) This is firstly useful in thinking about the type of deactivation that may be occurring-traditionally classified into (i) site blocking, (ii) encapsulation or (iii) pore blocking [51]. Here, the substantial volume difference makes (ii) and/or (iii) very likely. Secondly it useful

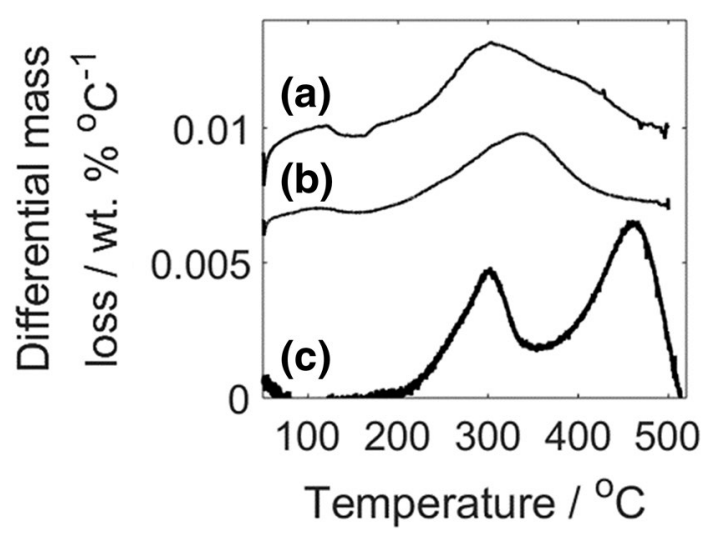

Fig. 12 Differential mass loss during TGA in flowing air of a silica exposed under reaction conditions to furfural $\left(5^{\circ} \mathrm{C} \mathrm{min}^{-1}\right)$; b silica exposed under reaction conditions to furfuryl alcohol $\left(5^{\circ} \mathrm{C} \mathrm{min}^{-1}\right)$; c spent $\mathrm{Ni} / \mathrm{SiO}_{2}\left(2{ }^{\circ} \mathrm{C} \mathrm{min}^{-1}\right)$ in interpretation of the mass loss features that occur during TPO: even if $\mathrm{Ni}$ assists in the formation of the coke species, most of the coke present is not directly on the surface of the $\mathrm{Ni}$ (which may also remain inaccessible) during the TPO measurement. We can then reasonably assign the two features seen on the basis of TPO of polymer silica composite materials in the literature. The desorption feature seen in both the silica-only and spent $\mathrm{Ni} / \mathrm{SiO}_{2}$ samples at around $300{ }^{\circ} \mathrm{C}$ is very consistent with that seen during TGA in air for low coverages of poly(furfuryl alcohol) deposited on MCM-41 (a microporous silica material) [52]. In the same study, higher coverages of poly(furfuryl alcohol) produce a second peak at around $480{ }^{\circ} \mathrm{C}$. While the nature of the second peak is unclear in the case of poly(furfuryl alcohol), the temperature range suggests it is more similar to long chain hydrocarbons such as the decomposition in air of low density polyethylene (either alone or in a composite with silica), which occurs at around $450{ }^{\circ} \mathrm{C}$ [53]. In the $\mathrm{Ni} / \mathrm{SiO}_{2}$ sample, the $\sim 450{ }^{\circ} \mathrm{C}$ feature only occurs in the presence of $\mathrm{Ni}$, and so can be ascribed to a different form of coke species from the lower temperature feature. Guisnet and Magnoux identified that for reactions occurring on metal-oxide or metal/metaloxide hybrid catalysts at low temperatures $\left(<200{ }^{\circ} \mathrm{C}\right)$, coke components mainly involve rearrangement and condensation reactions of the reactants and products, rather than the formation of polyaromatics [54]. The presence of $\mathrm{Ni}$ and hydrogen can also be expected to catalyse reactions such as hydrogenation, dehydrogenation, or dehydration. While the acid catalysed formation of polymers from the reactant and product appears consistent with the $300{ }^{\circ} \mathrm{C}$ peak (which occurs with or without $\mathrm{Ni}$ ) and may possibly contribute to the higher temperature peak observed when $\mathrm{Ni}$ is present, the peak at $450{ }^{\circ} \mathrm{C}$ is consistent with any higher molecular hydrocarbons ("polyethylene-like") that result from the dehydration of these initially formed polymers. The presence of at least some oxygenated species mirrors the observation of several carbon binding energies with XPS (assigned to ether/alcohol and carbonyl) by Marshall and co-workers on post-furfural hydrogenation copper chromite catalysts [11].

Further insight into the nature of species deposited on the catalyst came by solvent extraction of soluble species from the post-reaction $\mathrm{Ni} / \mathrm{SiO}_{2}$ catalyst. A Soxhlet extraction was conducted to remove any soluble species, before analysing the extracted species with GC-MS. After concentrating the extracts sufficiently for GC-MS determination, it should be noted a trace insoluble residue remained on the flask and could not be analysed. A number of peaks in the GC trace were identified as long chain hydrocarbons based on the regular spacing of one methylene unit between peaks (see example in Fig. 13a). Some of these could be identified from their parent ions as $\mathrm{C}_{21} \mathrm{H}_{44}, \mathrm{C}_{22} \mathrm{H}_{46}, \mathrm{C}_{23} \mathrm{H}_{48}$, and, $\mathrm{C}_{24} \mathrm{H}_{50}$. Another species was observed at lower retention times by GC-MS, exhibiting clear fragments at $\mathrm{m} / \mathrm{z}=167$, 

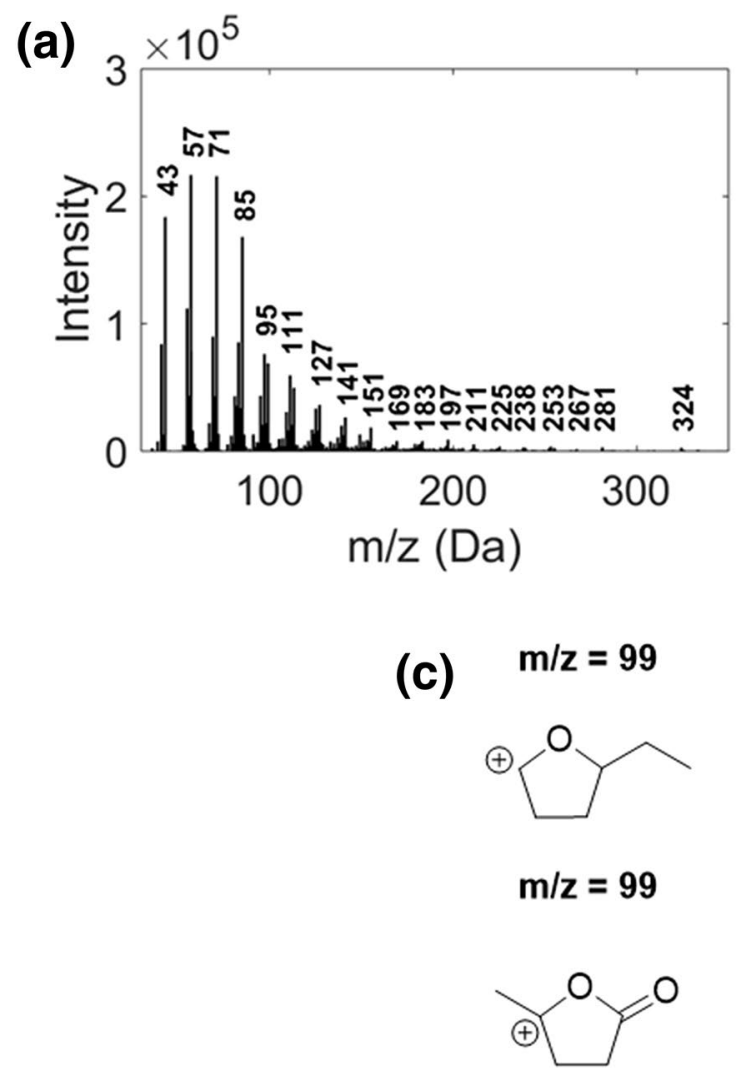

Fig. 13 GC-MS mass spectra $(\mathrm{m} / \mathrm{z}$ 35-350) of species extracted from spent $\mathrm{Ni} / \mathrm{SiO}_{2}$ catalyst using a Soxhlet extraction: a example of a mass spectrum of a long chain hydrocarbon (consistent with tricosane; $\mathrm{C}_{23} \mathrm{H}_{48}$ ); b mass spectrum of lower retention time peak

155, 139, 99, 57, and 41 (Fig. 13b). Although a definitive assignment cannot be made (as several combinations of fragments fit the data) the dominant $\mathrm{m} / \mathrm{z}=155$ and 99 features (and absence of $\mathrm{m} / \mathrm{z} /=71$ implying this isn't a linear hydrocarbon fragment) indicate the likelihood of this belonging to either ring opened furanic oligomers or hydrogenated linear oligomers of furfuryl alcohol. Possible fragments are suggested in Fig. 13c. A wide range of such structures have been proposed for furfuryl alcohol oligomers formed over acidic solids such as $\mathrm{Al}_{2} \mathrm{O}_{3}$ or $\mathrm{WO}_{3}$.[55, 56] Comparison to a solvent blank confirmed none of these peaks were present in the extraction solvent.

Further analysis of species deposited on the catalyst was conducted using DRIFTS. In order to distinguish between species present on the support and species present on the metal, the silica and a sample of nickel powder were exposed to furfural, furfuryl alcohol or products under standard furfural hydrogenation conditions. The DRIFT spectra of the nickel powder samples contained no significant peaks, likely due to the low surface area of the material. However, infrared absorption bands were observed for the silica samples

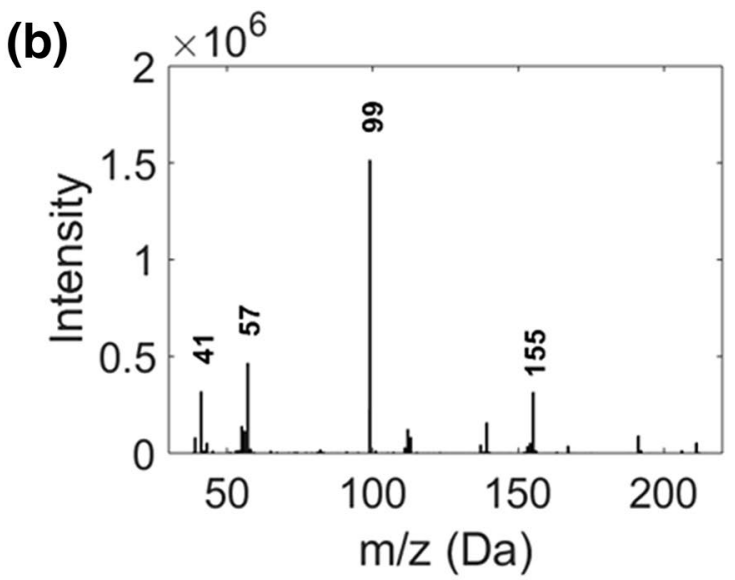

$\mathrm{m} / \mathrm{z}=155$

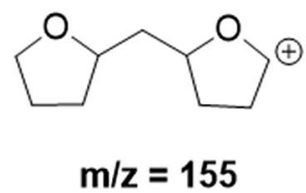<smiles>[C+]C(C=O)CC(=O)C(=O)CC</smiles>

attributed to hydrogenated furanic or ring opened furanic oligomers, c possible hydrogenated components of short chain furanic oligomers contributing to the spectrum in (b)

(see Fig. 14). The peaks observed in the spectrum of silica exposed to furfural matched well with the reference furfural spectrum, with only some small shifts in peak position, likely due to interactions with the support or oligomerisation. The spectrum for silica exposed to furfuryl alcohol contained similar infrared bands to those observed in the spent $\mathrm{Ni} / \mathrm{SiO}_{2}$ catalyst, with two very broad peaks in the $1350-2000 \mathrm{~cm}^{-1}$ region and four weak peaks in the $\mathrm{C}-\mathrm{H}$ region $\left(2800-3000 \mathrm{~cm}^{-1}\right)$. Therefore, one of the coke species present is likely related to furfuryl alcohol or its oligomers. The furfuryl alcohol reference spectrum generally has weak signals, however there is a sharp peak at $1504 \mathrm{~cm}^{-1}$ which has been assigned as $\mathrm{C}=\mathrm{C}$ stretching [57]. This sharper signal was not present in either the silica exposed to furfuryl alcohol or the spent $\mathrm{Ni} / \mathrm{SiO}_{2}$, perhaps due to interaction of furfuryl alcohol with the silica or oligomerisation. Some examples of furfuryl alcohol polymers are shown in Fig. 15, although other versions such as cross-linked polymers are known [56].

Changing the support to titania and ceria did not have a significant effect on the peaks observed in the DRIFT 

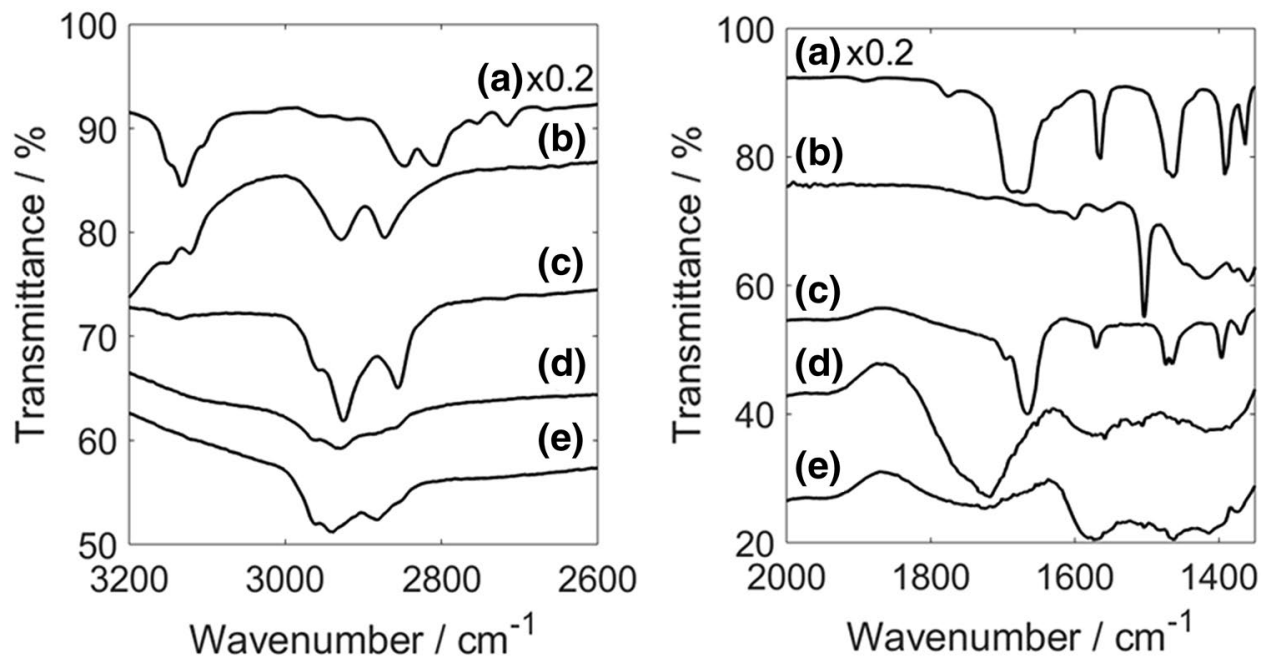

Fig. 14 Infrared spectra showing (3200-2600 $\mathrm{cm}^{-1}$ left, 2000$1350 \mathrm{~cm}^{-1}$ right): (a) Furfural reference spectrum [58], multiplied by 0.2 for comparison. (b) Furfuryl alcohol reference spectrum (ATR),

(c) Silica exposed to furfural (DRIFTS), (d) Silica exposed to furfu- ryl alcohol (DRIFTS), (e) spent $\mathrm{Ni} / \mathrm{SiO}_{2}$ catalyst (DRIFTS). Spectra (b-e) offset vertically for clarity. For (c) and (d) furfural or furfural alcohol were fed into the reactor under otherwise standard catalyst testing conditions with only the support rather than a catalyst present
Fig. 15 Examples of possible furfuryl alcohol polymers [56]

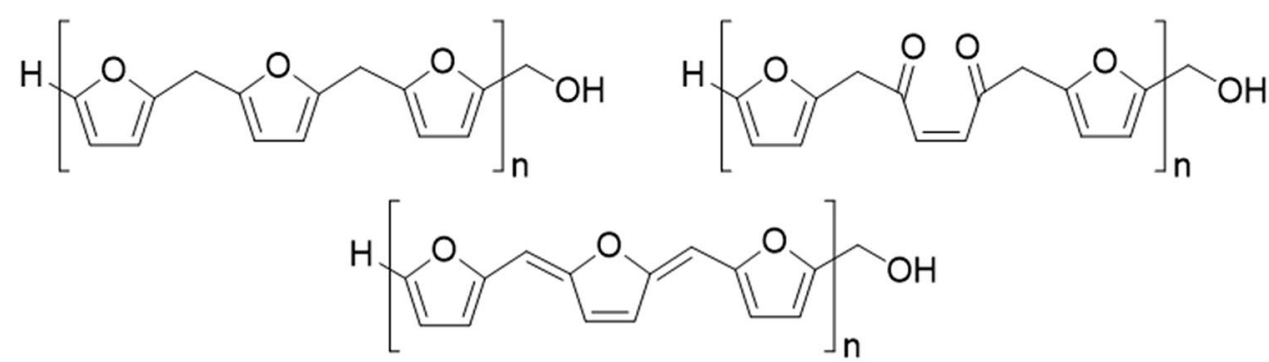

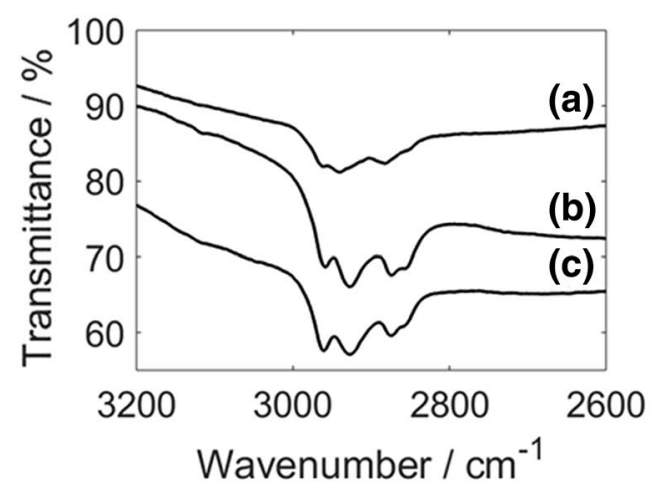

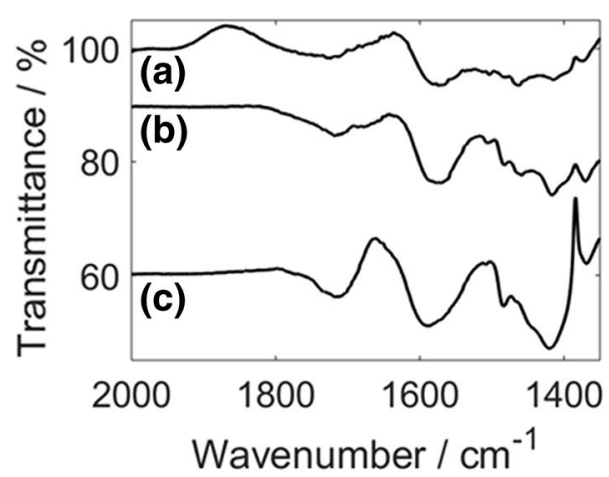

Fig. 16 DRIFTS spectra (3200-2600 $\mathrm{cm}^{-1}$ left, 2000$1350 \mathrm{~cm}^{-1}$ right); (a) spent $\mathrm{Ni} /$ $\mathrm{SiO}_{2}$; (b) spent $\mathrm{Ni} / \mathrm{TiO}_{2}$; (c) spent $\mathrm{Ni} / \mathrm{CeO}_{2}$. Spectra offset for vertically clarity spectra (see Fig. 16), suggesting that similar coke species are present in all catalysts and that these species are likely related to furfuryl alcohol. It should be remembered that differences in intensity in DRIFTS do not necessarily correlate cleanly with concentration due to different transmittances of the samples. (Note the small feature around $1900 \mathrm{~cm}^{-1}$ seen for silica but not the other two supports is due to the silica itself, and is commonly seen for dehydrated silica [59].) The similarity across all supports fits with the fact that changing the support had little effect on the selectivity and deactivation of the catalysts. If the finding by infrared that the main species seen are furfuryl alcohol-like is considered relative to the TPO and GC-MS data above, it must be remembered that the presence of long chain hydrocarbons is hard to see by infrared, with the only distinguishing features likely to be in the same region as the $\mathrm{C}-\mathrm{H}$ stretches already seen. Furthermore, if the more deoxygenated coke forms in the pores around the nickel it may be less evenly distributed than 
Fig. 17 DRIFTS spectra (3200-2600 $\mathrm{cm}^{-1}$ left, 2000$1350 \mathrm{~cm}^{-1}$ right); (a) spent $\mathrm{Ni} /$ $\mathrm{SiO}_{2}$; (b) spent copper chromite. Spectra offset for vertically clarity

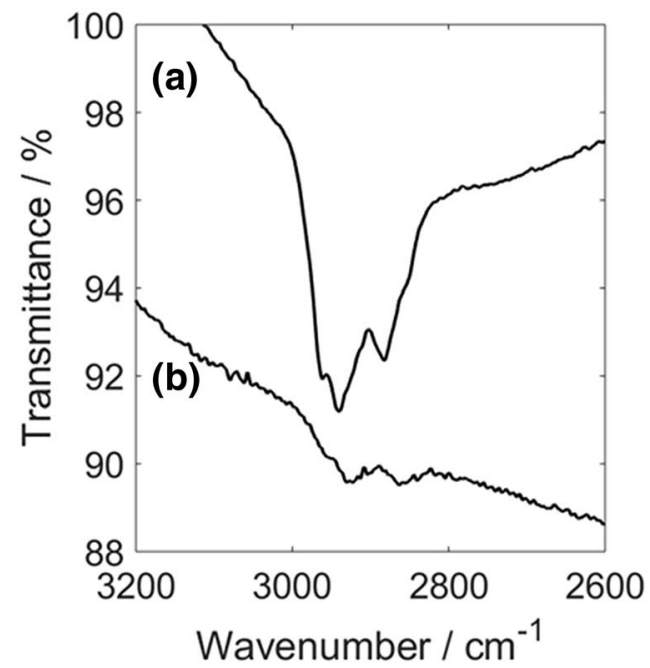

the oligomers formed over silica alone, which in turn may make the long-chain hydrocarbons less readily probed during DRIFTS measurements that result from light reflecting off multiple surfaces in the sample [60]. An overall model for deactivation therefore likely involves both condensation to form oligomers and polymers of the product (and perhaps reactant), followed by $\mathrm{Ni}$ catalysed hydrogenation and dehydration to produce deoxygenated coke. The volume of coke is sufficient to encapsulate the nickel or block access via the pores of the silica and gradually results in a large fractional loss of activity over $\sim 10 \mathrm{~h}$ TOS.

The spent copper chromite sample, which exhibited a smaller amount of carbon deposition (Table 3) than the other samples also has much weaker bands in the infrared (Fig. 17), both attributable to the low surface area, versus the nickel catalysts that were deposited on known high surface area supports. The infrared spectra show bands in the C-H stretching region $\left(\sim 2850-3000 \mathrm{~cm}^{-1}\right)$, although with slight differences from the nickel samples. This suggests the possibility that different oligomeric species are formed as the dominant carbon containing products, is highly feasible given the change of catalyst, but their presence again supports the formation of hydrocarbons as well as purely carbonaceous coke.

\section{Conclusions}

In summary, supported nickel catalysts were found to produce furfuryl alcohol as the dominant product with a selectivity of $\sim 50 \%$ during vapour phase furfural hydrogenation. $\mathrm{A} \mathrm{Ni} / \mathrm{SiO}_{2}$ catalyst is seen to be significantly more active than pure copper chromite, but exhibits much poorer selectivity when tested under comparable conditions. The deactivation behaviours of $\mathrm{Ni} / \mathrm{SiO}_{2}$ and copper chromite were found to be remarkably similar as a function of time on stream. Subjecting the $\mathrm{Ni} / \mathrm{SiO}_{2}$ catalyst before and after reaction to $\mathrm{pXRD}$ did not show a particle size change significant enough for nickel sintering to account for the decrease in catalyst activity. $\mathrm{Ni} / \mathrm{TiO}_{2}$ and $\mathrm{Ni} / \mathrm{CeO}_{2}$ exhibited similar deactivation profiles, indicating acidic sites on the catalyst support are not strongly implicated in the deactivation occurring. TPO, infrared and solvent extraction of spent catalysts provides evidence that deactivation is likely the result of the gradual formation of oligomeric/polymeric forms of the product (or reactant) and their deoxygenation to hydrocarbons. TPO indicates about 30 wt. \% of coke is present after the catalyst has been deactivated by an order of magnitude, with a split between reactant/product-like polymeric species and deoxygenated hydrocarbons. Overall, the high activity seen points to the potential for developing new catalysts based on nickel for this important platform-chemical processing reaction, but two important areas for further work are identified as: (1) tuning the selectivity of the nickel, perhaps at the expense of some of its high hydrogenation reactivity, and (2) preventing the oligomerisation and deoxygenation steps that result in deactivation by coking of the catalyst.

Acknowledgements We gratefully acknowledge assistance from $\mathrm{Mr}$ P. Stokes and Dr L. Li with GCMS and BET measurements, respectively, and TEM access provided through the Durham University GJ Russell Microscopy Facility. KLM acknowledges the UK Engineering and Physical Sciences Research Council (EP/R513039/1) for funding.

Funding UK Engineering and Physical Sciences Research Council (EP/R513039/1).

Data Availability Raw data files associated with the data presented in this manuscript are available from Durham Research Online DATA: https://doi.org/10.15128/r1jd472w47k. 


\section{Compliance with Ethical Standards}

Conflict of interest All authors declare that they have no conflict of interest or financial ties to declare.

Open Access This article is licensed under a Creative Commons Attribution 4.0 International License, which permits use, sharing, adaptation, distribution and reproduction in any medium or format, as long as you give appropriate credit to the original author(s) and the source, provide a link to the Creative Commons licence, and indicate if changes were made. The images or other third party material in this article are included in the article's Creative Commons licence, unless indicated otherwise in a credit line to the material. If material is not included in the article's Creative Commons licence and your intended use is not permitted by statutory regulation or exceeds the permitted use, you will need to obtain permission directly from the copyright holder. To view a copy of this licence, visit http://creativecommons.org/licenses/by/4.0/.

\section{References}

1. Cherubini F (2010) The biorefinery concept: using biomass instead of oil for producing energy and chemicals. Energy Convers Manage 51:1412-1421

2. Bozell JJ, Petersen GR (2010) Technology development for the production of biobased products from biorefinery carbohydratesthe US Department of Energy's “Top 10" revisited. Green Chem 12:539-554

3. Elliott DC, Hart TR (2009) Catalytic hydroprocessing of chemical models for bio-oil. Energy Fuels 23:631-637

4. Yan K, Wu G, Lafleur T, Jarvis C (2014) Production, properties and catalytic hydrogenation of furfural to fuel additives and valueadded chemicals. Renew Sustain Energy Rev 38:663-676

5. Gallezot P (2012) Conversion of biomass to selected chemical products. Chem Soc Rev 41:1538-1558

6. Climent MJ, Corma A, Iborra S (2014) Conversion of biomass platform molecules into fuel additives and liquid hydrocarbon fuels. Green Chem 16:516-547

7. Mandalika A, Qin L, Sato TK, Runge T (2014) Integrated biorefinery model based on production of furans using open-ended high yield processes. Green Chem 16:2480-2489

8. Besson M, Gallezot P, Pinel C (2014) Conversion of biomass into chemicals over metal catalysts. Chem Rev 114:1827-1870

9. Egeblad K, Rass-Hansen J, Marsden CC, Taarning E, Hviid Christensen C (2009) Heterogeneous catalysis for production of valueadded chemicals from biomass. In: Spivey JJ, Dooley KM (eds) Catalysis, vol 21. The Royal Society of Chemistry, Cambridge, pp 13-50

10. Zhang H, Canlas C, Jeremy Kropf A, Elam JW, Dumesic JA, Marshall CL (2015) Enhancing the stability of copper chromite catalysts for the selective hydrogenation of furfural with ALD overcoating (II) - comparison between $\mathrm{TiO}_{2}$ and $\mathrm{Al}_{2} \mathrm{O}_{3}$ overcoatings. J Catal 326:172-181

11. Liu D, Zemlyanov D, Wu T, Lobo-Lapidus RJ, Dumesic JA, Miller JT, Marshall CL (2013) Deactivation mechanistic studies of copper chromite catalyst for selective hydrogenation of 2-furfuraldehyde. J Catal 299:336-345

12. Pushkarev VV, Musselwhite N, An KJ, Alayoglu S, Somorjai GA (2012) High structure sensitivity of vapor-phase furfural decarbonylation/hydrogenation reaction network as a function of size and shape of Pt nanoparticles. Nano Lett 12:5196-5201

13. Rogers SM, Catlow CRA, Chan-Thaw CE, Chutia A, Jian N, Palmer RE, Perdjon M, Thetford A, Dimitratos N, Villa A, Wells
PP (2017) Tandem site- and size-controlled Pd nanoparticles for the directed hydrogenation of furfural. ACS Catal 7:2266-2274

14. Taylor MJ, Jiang L, Reichert J, Papageorgiou AC, Beaumont SK, Wilson K, Lee AF, Barth JV, Kyriakou G (2017) Catalytic hydrogenation and hydrodeoxygenation of furfural over $\mathrm{Pt}(111)$ : A model system for the rational design and operation of practical biomass conversion catalysts. J Phys Chem C 121:8490-8497

15. Taylor MJ, Durndell LJ, Isaacs MA, Parlett CMA, Wilson K, Lee AF, Kyriakou G (2016) Highly selective hydrogenation of furfural over supported Pt nanoparticles under mild conditions. Appl Catal, B 180:580-585

16. Li MS, Hao YF, Cardenas-Lizana F, Keane MA (2015) Selective production of furfuryl alcohol via gas phase hydrogenation of furfural over $\mathrm{Au} / \mathrm{Al}_{2} \mathrm{O}_{3}$. Catal Commun 69:119-122

17. Chorkendorff I, Niemantsverdriet JW (2007) Concepts of modern catalysis and kinetics, 2nd edn. Wiley-VCH, Weinheim

18. van Santen RA, Niemantsverdriet HW (1995) Chemical kinetics and catalysis. Springer, US, New York

19. Rostrup-Nielsen JR, Sehested J, Nørskov JK (2002) Hydrogen and synthesis gas by steam- and $\mathrm{CO}_{2}$ reforming. Adv Catal 47:65-139

20. Bengaard HS, Norskov JK, Sehested J, Clausen BS, Nielsen LP, Molenbroek AM, Rostrup-Nielsen JR (2002) Steam reforming and graphite formation on Ni catalysts. J Catal 209:365-384

21. McFarlane AR, Silverwood IP, Norris EL, Ormerod RM, Frost CD, Parker SF, Lennon D (2013) The application of inelastic neutron scattering to investigate the steam reforming of methane over an alumina-supported nickel catalyst. Chem Phys 427:54-60

22. Gong WB, Chen C, Zhang HM, Zhang Y, Zhang YX, Wang GZ, Zhao HJ (2017) Highly selective liquid-phase hydrogenation of furfural over $\mathrm{N}$-doped carbon supported metallic nickel catalyst under mild conditions. Mol Catal 429:51-59

23. O'Driscoll A, Leahy JJ, Curtin T (2017) The influence of metal selection on catalyst activity for the liquid phase hydrogenation of furfural to furfuryl alcohol. Catal Today 279:194-201

24. Sang SY, Wang Y, Zhu W, Xiao GM (2017) Selective hydrogenation of furfuryl alcohol to tetrahydrofurfuryl alcohol over $\mathrm{Ni} /$ gamma- $\mathrm{Al}_{2} \mathrm{O}_{3}$ catalysts. Res Chem Intermed 43:1179-1195

25. Su Y, Chen C, Zhu X, Zhang Y, Gong W, Zhang H, Zhao H, Wang G (2017) Carbon-embedded Ni nanocatalysts derived from MOFs by a sacrificial template method for efficient hydrogenation of furfural to tetrahydrofurfuryl alcohol. Dalton Trans 46:6358-6365

26. Gong W, Chen C, Zhang H, Wang G, Zhao H (2018) Highly dispersed $\mathrm{Co}$ and $\mathrm{Ni}$ nanoparticles encapsulated in $\mathrm{N}$-doped carbon nanotubes as efficient catalysts for the reduction of unsaturated oxygen compounds in aqueous phase. Catal Sci Technol 8:5506-5514

27. Xu Y, Qiu S, Long J, Wang C, Chang J, Tan J, Liu Q, Ma L, Wang $\mathrm{T}$, Zhang Q (2015) In situ hydrogenation of furfural with additives over a RANEY Ni catalyst. RSC Adv 5:91190-91195

28. Srivastava S, Jadeja GC, Parikh J (2017) Synergism studies on alumina-supported copper-nickel catalysts towards furfural and 5-hydroxymethylfurfural hydrogenation. J Mol Catal A: Chem 426:244-256

29. Jia P, Lan X, Li X, Wang T (2018) Highly active and selective $\mathrm{NiFe} / \mathrm{SiO}_{2}$ bimetallic catalyst with optimized solvent effect for the liquid-phase hydrogenation of furfural to furfuryl alcohol. ACS Sustainable Chem Eng 6:13287-13295

30. Rodiansono AMD, Mujiyanti DR, Santoso UT, Shimazu S (2018) Novel preparation method of bimetallic Ni-In alloy catalysts supported on amorphous alumina for the highly selective hydrogenation of furfural. Mol Catal 445:52-60

31. Vetere V, Merlo AB, Ruggera JF, Casella ML (2010) Transition metal-based bimetallic catalysts for the chemoselective hydrogenation of furfuraldehyde. J Braz Chem Soc 21:914-920 
32. Manikandan M, Venugopal AK, Prabu K, Jha RK, Thirumalaiswamy R (2016) Role of surface synergistic effect on the performance of Ni-based hydrotalcite catalyst for highly efficient hydrogenation of furfural. J Mol Catal A: Chem 417:153-162

33. Nakagawa $Y$, Nakazawa H, Watanabe H, Tomishige K (2012) Total hydrogenation of furfural over a silica-supported nickel catalyst prepared by the reduction of a nickel nitrate precursor. ChemCatChem 4:1791-1797

34. Sulmonetti TP, Pang SH, Claure MT, Lee S, Cullen DA, Agrawal PK, Jones CW (2016) Vapor phase hydrogenation of furfural over nickel mixed metal oxide catalysts derived from layered double hydroxides. Appl Catal, A 517:187-195

35. Madduluri VR, Mandari KK, Velpula V, Varkolu M, Kamaraju SRR, Kang M (2020) Rice husk-derived carbon-silica supported $\mathrm{Ni}$ catalysts for selective hydrogenation of biomass-derived furfural and levulinic acid. Fuel. https://doi.org/10.1016/j. fuel.2019.116339

36. Vargas-Hernández D, Rubio-Caballero JM, Moreno-Tost R, Mérida-Robles JM, Santamaría-González J, Jiménez-López A, Pérez-Cruz MA, Hernández-Huesca R, Maireles-Torres P (2016) Vapor phase decarbonylation of furfural to furan over nickel supported on SBA-15 silica catalysts. Mod Res Catal 05:85-94

37. Armarego WLF, Chai C (2013) Purification of laboratory chemicals, 7th edn. Butterworth-Heinemann, Boston

38. Pirez C, Caderon J-M, Dacquin J-P, Lee AF, Wilson K (2012) Tunable KIT-6 mesoporous sulfonic acid catalysts for fatty acid esterification. ACS Catal 2:1607-1614

39. Ren Y, Ma Z, Qian L, Dai S, He H, Bruce PG (2009) Ordered crystalline mesoporous oxides as catalysts for $\mathrm{CO}$ oxidation. Catal Lett 131:146-154

40. Deng X, Chen K, Tüysüz H (2017) Protocol for the nanocasting method: preparation of ordered mesoporous metal oxides. Chem Mater 29:40-52

41. Rao R, Dandekar A, Baker RTK, Vannice MA (1997) Properties of copper chromite catalysts in hydrogenation reactions. J Catal 171:406-419

42. Tauster SJ, Fung SC, Garten RL (1978) Strong metal-support interactions. Group 8 noble metals supported on titanium dioxide. J Am Chem Soc 100:170-175

43. Chung Y-W, Xiong G, Kao C-C (1984) Mechanism of strong metal-support interaction in $\mathrm{NiTiO}_{2}$. J Catal 85:237-243

44. Louis C, Cheng ZX, Che M (1993) Characterization of nickel/ silica catalysts during impregnation and further thermal activation treatment leading to metal particles. J Phys Chem 97:5703-5712

45. Zeitsch KJ (2000) The chemistry and technology of furfural and its many by-products, 1st edn. Elselvier Science, Amersterdam

46. Rostrup-Nielsen JR (1984) Sulfur-passivated nickel catalysts for carbon-free steam reforming of methane. J Catal 85:31-43

47. Nagaraja BM, Siva Kumar V, Shasikala V, Padmasri AH, Sreedhar B, David Raju B, Rama Rao KS (2003) A highly efficient
$\mathrm{Cu} / \mathrm{MgO}$ catalyst for vapour phase hydrogenation of furfural to furfuryl alcohol. Catal Commun 4:287-293

48. Santacesaria E, Carotenuto G, Tesser R, Di Serio M (2012) Ethanol dehydrogenation to ethyl acetate by using copper and copper chromite catalysts. Chem Eng J 179:209-220

49. Monnier JR, Hanrahan MJ, Apai G (1985) A study of the catalytically active copper species in the synthesis of methanol over $\mathrm{Cu}-\mathrm{Cr}$ oxide. J Catal 92:119-126

50. Kijenski J, Baiker A (1989) Acidic sites on catalyst surfaces and their determination. Catal Today 5:1-120

51. Bartholomew CH (2001) Mechanisms of catalyst deactivation. Appl Catal A 212:17-60

52. Janus R, Wach A, Kuśtrowski P, Dudek B, Drozdek M, SilvestreAlbero AM, Rodríguez-Reinoso F, Cool P (2013) Investigation on the low-temperature transformations of poly(furfuryl alcohol) deposited on MCM-41. Langmuir 29:3045-3053

53. Sertchook H, Elimelech H, Makarov C, Khalfin R, Cohen Y, Shuster M, Babonneau F, Avnir D (2007) Composite particles of polyethylene @ silica. J Am Chem Soc 129:98-108

54. Guisnet M, Magnoux P (2001) Organic chemistry of coke formation. Appl Catal A 212:83-96

55. Wewerka EM (1971) Study of the $\gamma$-alumina polymerization of furfuryl alcohol. J Polym Sci Part A-1 Polym Chem 9:2703-2715

56. Tondi G, Cefarin N, Sepperer T, D’Amico F, Berger RJF, Musso M, Birarda G, Reyer A, Schnabel T, Vaccari L (2019) Understanding the polymerization of polyfurfuryl alcohol: ring opening and diels-alder reactions. Polymers 11:2126

57. Araujo-Andrade C, Gómez-Zavaglia A, Reva ID, Fausto R (2012) Conformers, infrared spectrum and UV-induced photochemistry of matrix-isolated furfuryl alcohol. J Phys Chem A 116:2352-2365

58. Wallace WE, NIST Mass Spectrometry Data Center (2020) Infrared spectra. In: Linstrom PJ, Mallard WG (eds) NIST chemistry WebBook. NIST Standard Reference Database Number 69. https ://doi.org/10.18434/T4D303. National Institute of Standards and Technology, Gaithersburg MD. (Accessed May 23, 2020)

59. Chukin GD, Malevich VI (1977) Infrared spectra of silica. J Appl Spectrosc 26:223-229

60. Armaroli T, Bécue T, Gautier S (2004) Diffuse reflection infrared spectroscopy (DRIFTS): application to the in situ analysis of catalysts. Oil Gas Sci Technol 59:215-237

Publisher's Note Springer Nature remains neutral with regard to jurisdictional claims in published maps and institutional affiliations. 